\title{
Notice
}

This is an Authors' Accepted Manuscript of an article published online 7 February 2015: Van Gelderen, M., Kautonen, T. and Fink, M. (2015). From entrepreneurial intentions to actions: selfcontrol and action-related doubt, fear, and aversion. Journal of Business Venturing, 30(5), 655673. (C) Elsevier

Changes introduced as a result of copy-editing, formatting and other publishing processes may not be reflected in this document. For a definitive version of this work, please refer to the published source: http://dx.doi.org/10.1016/j.jbusvent.2015.01.003.

\section{From entrepreneurial intentions to actions: Self-control and action-related doubt, fear, and aversion}

\begin{abstract}
This study draws on the Rubicon model of action phases to study the actions or lack of actions that follow the formation of entrepreneurial intentions. Concurrently, it examines the roles of self-control and action-related emotions in explaining the intention-action gap using longitudinal survey data. The results show that self-control positively moderates the relationship between intention and action, and that it counters the rise of action-related fear, doubt, and aversion. We also find evidence for interaction effects between action aversion, action doubt, and intention strength. Our results signal the importance of studying moderators of the intention-action relationship.
\end{abstract}

\section{Executive summary}

Many people form intentions to start their own business but do little to translate those intentions into actions. Acting upon intentions may be postponed or abandoned because new constraints emerge or the person's preferences change. However, if an aspiring entrepreneur does not take action despite ongoing intentions, potentially fruitful entrepreneurial ventures are not realized. 
For this reason it is important to understand the so-called intention-action gap and to investigate under what conditions people turn their start-up intentions into actions or fail to do so.

This study builds on the theory of planned behavior (Ajzen, 1991; 2011/2014) and prior entrepreneurial intentions research (Schlaegel and Koenig, 2014) by drawing on the Rubicon model of action phases (Gollwitzer, 1990; 2012; Heckhausen and Gollwitzer, 1987) to study the actions, or lack of actions, that follow the formation of entrepreneurial intentions. The starting point for the analysis is that forming a strong intention is only a preliminary stage of successful goal attainment, because a host of subsequent implementation issues remain to be resolved (Gollwitzer and Sheeran, 2006). In this study we focus on volition: how individuals exercise willpower to obtain what they desire plays a key role in dealing with these implementation issues. This analysis focuses on two sets of constructs related to volition: (1) action-related emotions (doubt, fear, and aversion) may cause people to avoid action and willpower will then be required to overcome their stifling effects; (2) self-control is a personality disposition that reflects an individual's capacity to exercise willpower.

The empirical analysis is based on longitudinal survey data from a random sample of the Finnish population. Intentions to engage in start-up activities in the following 12 months and self-control were measured in the first wave. The second survey was administered one year later and inquired about the start-up activities undertaken and the action-related emotions encountered from those 161 individuals who reported a positive (non-zero) intention in the first wave. The results show that self-control positively moderates the relationship between intention and action, and that it counters the rise of action-related fear, doubt, and aversion. In other words, an intention to 
engage in start-up activity is more likely to lead to subsequent action when an individual has a high level of self-control. Having a high level of self-control also makes it less likely that the person will experience high levels of any of the avoidance-oriented action-related emotions.

These findings offer an insight into when and why entrepreneurial intentions are followed by actions. They also extend intention research by providing new insights into the behavioral processes that follow the formation of an intention to start a business. In practical terms our research highlights the essential role of self-control in the implementation of entrepreneurial intentions, and the importance of applying action knowledge and action planning to avoid action doubt stifling entrepreneurial action.

\section{Introduction}

Sue has been talking about establishing her own nursery business for some years now. She is in her forties and married with two children. Having completed her master's degree in education, she began working in a municipal nursery school, and became its principal five years later. Yesterday, a friend asked her what happened to her intentions to start her own nursery business. Initially, Sue did not really know what to say; then she recalled how busy she had been in the past few years with her family, work, and volunteering with her local church. Somehow, she never had enough time and energy to get started with her business idea. She also mentioned that when she had thought about pushing ahead with the business idea, she had struggled to see where to start. It also turned out that she found the paperwork required to set up a business daunting and was worried what would happen to her family if the business were not successful. 
The fictional example of Sue's case illustrates a relatively common scenario: many people form an intention to start their own business but do little to translate their intention into actions, and that lack of action is not uncommon among aspiring entrepreneurs. Research on nascent entrepreneurship in the United States shows some people lingering for long periods in what Reynolds (2000) referred to as the still-trying phase. One piece of research cites five extreme examples where the prospective entrepreneurs waited nearly 50 years before finally acting on their intentions (Liao and Welsch, 2008, p. 112). By definition, intentions concern future goals and actions, and there is no conflict between intention and a lack of subsequent action if acting upon the intention was deliberately postponed, or if new constraints emerged or preferences changed that led a person to abandon the intention. However, if no action is taken in spite of ongoing intentions, intentions and actions will be at odds with each other. A lack of action then means that potentially fruitful entrepreneurial initiatives are not realized. Entrepreneurial action is not only a necessary condition to get businesses started, but is also important in determining if an attempt to start a new venture will ultimately be abandoned. Research on nascent entrepreneurs shows that those who quit the start-up process will generally have taken more action than those who linger in the still-trying phase. The former will often have prepared for and investigated a new venture before deciding to abandon the idea; whereas the latter group are likely to have taken little action (Carter et al., 1996; Lichtenstein et al., 2007).

In entrepreneurship research, the dominant psychological theories used to predict and explain the emergence of new ventures are Ajzen's (1991; 2014) Theory of Planned Behavior (TPB) and Shapero and Sokol's (1982) Entrepreneurial Event Model (EEM). These models agree that the best way to determine if people will take action to start their own business is to ask them whether 
they intend to do so. Although numerous studies have examined the formation of entrepreneurial intentions (Schlaegel and Koenig, 2014), research on the intention-action link in the context of new venture creation has emerged only recently (Gielnik et al., 2014; Goethner et al., 2012; Kautonen et al., 2013). These studies indicate that although intentions are indeed a significant predictor of subsequent action, intentions only explain a certain proportion of the variation in the extent of action taken. Intention-action gaps are also found in other behavioral domains (Sheeran, 2002) ${ }^{1}$. There is compelling evidence that intention strength is not the only factor predicting the extent of action taken.

This article adds to the emerging understanding of the entrepreneurial intention-action relationship by complementing the study of intentions with constructs related to volition. A behavioral intention represents a person's motivation to perform a behavior, encompassing both the direction (to do X vs. not to do X) and the intensity (e.g., how much time and effort the person is prepared to invest in doing X) (Sheeran, 2002). Regulating the translation of intention into action, however, is also volitional (i.e., how individuals exercise willpower to attain what they desire) (Gollwitzer et al., 1990; Lord et al., 2010). From a self-regulatory perspective, forming a strong intention is only a prerequisite for successful goal attainment, because a host of subsequent implementation issues remain to be resolved (Gollwitzer and Sheeran, 2006).

\footnotetext{
${ }^{1}$ Although it is common for intention theories to refer to behavior, we will use the term action, with action being defined as the "fact or process of doing something, typically to achieve an aim" (Oxforddictionaries.com, 2014). The goal-directed and intentional nature of the behaviors we investigate (Bird, 1988) allows us to refer to these behaviors as actions.
} 
We extend intention research in the entrepreneurial context by studying the actions (or lack of actions) that follow the formation of intention. We do so by drawing on the Rubicon model of action phases (Gollwitzer, 1990; 2012; Heckhausen and Gollwitzer, 1987), which distinguishes motivational from volitional phases in the process of taking action. Volitional constructs are incorporated in the study in two ways: first in the form of action-related emotions (doubt, fear, and aversion) that may cause people to avoid action, and that require volitional capacities to overcome their stifling effects, and also as a personality disposition (trait self-control) that reflects volitional capacity. The relevant constructs are introduced in the next section of the study, which also outlines the proposed hypotheses. Those hypotheses are subsequently tested using longitudinal survey data drawn from the adult population of Finland.

\section{Volition and the entrepreneurial intention-action gap}

\subsection{The entrepreneurial intention-action gap}

In a recent meta-analysis, Schlaegel and Koenig (2014) analyzed the determinants of entrepreneurial intentions using 98 studies that involved 114,000 respondents. Having identified only two published studies that examined the intention-action link in the context of new venture creation, they recommended future research focus on the translation of intentions into subsequent actions. Although the 98 intention studies acknowledge that intentions are only an intermediate step on the route to entrepreneurial action, intentions are assumed to have predictive value. In the absence of evidence from entrepreneurship research, these studies justify their argument that intentions are a good predictor of behavior by referring either to theory or to empirical results from other research domains (e.g., Fitzsimmons and Douglas, 2011; Krueger et al., 2000; Zellweger et al., 2011). Indeed, in a meta-analysis of meta-analyses covering a wide variety of 
human behaviors, Sheeran (2002) found that intentions on average predict $28 \%$ of variation in subsequent behavior, a large effect size (Cohen, 1992). We argue, however, that the association between intentions and actions is likely to be weaker in the context of new venture creation.

There are various reasons for volition-related action problems arising after the formation of an entrepreneurial intention. The intention to start a new venture is typically formed at the venture (goal) level, and not at the level of each individual action required to start the venture.

Consequently, relatively abstract and generic assessments of the desirability and feasibility of the venture determine the goal intention. Furthermore, starting a new business involves numerous activities of varying complexity. The studies included in Sheeran's (2002) meta-analysis mainly concerned relatively simple and discrete acts, such as voting, dieting, exercise, and condom use. In comparison, Sheeran's analysis shows that the intention-action correlation is higher for single acts than for goal intentions requiring complex constellations of actions. Moreover, his study shows that intentions predict behavior far better when the time frame is short, rather than long. In light of this evidence, the claim made by Krueger et al. (2000) and Souitaris et al. (2007) that intentions are the best predictor of entrepreneurial action in the case of unpredictable time lags seems doubtful. Higher-level goals, even if recognized to be of utmost importance, are often not always the focus of attention (Frese, 2007). Short-term goals may have more regulatory power, which results in procrastination relating to actions connected to medium-term goals such as new venture creation (Steel, 2007).

Entrepreneurial goal intentions can span a long or even an indeterminate time frame. The longer the time frame, the more desirability aspects drive the intention (Eyal et al., 2004; Trope and 
Liberman, 2010). Schlaegel and Koenig's (2014) meta-analysis showed that in TPB-based studies, attitude (a TPB construct related to the desirability of the target behavior) is the most important predictor of entrepreneurial intentions. It may only be at a later stage, perhaps when implementing the actions to achieve their goals, that entrepreneurs direct their attention to the specific actions required (and their incidental, and context-dependent properties), and at that point action-related implementation problems can arise. The realization of the magnitude and of the intricacy of the task may then induce procrastination (Liberman et al., 2007; McCrea et al., 2008).

As a consequence, the intention-action link may be weaker in the context of new venture creation than in many other domains. It cannot be assumed that entrepreneurial intentions are necessarily followed by actions. In fact, the data collected for the current research show that $69 \%$ of the prospective entrepreneurs in the sample take little or no action in the year following stating their intention to engage in start-up activities. This fact raises the question of what influences the intention-action gap in entrepreneurship. Why do some people act on their intentions, whereas others do not? In this study, intentions are considered only the starting point of actions, and we investigate whether volition plays a role in the translation of intentions into actions. Our study is guided by the Rubicon model of action phases (Gollwitzer, 1990; 1999; 2012; Heckhausen and Gollwitzer, 1987), which distinguishes motivational and volitional phases in the process of taking action.

\subsection{The Rubicon model of action phases}


The Rubicon model of action phases holds that distinct psychological principles govern the processes of goal setting and goal striving (Gollwitzer, 1990, 1999, 2012; Heckhausen and Gollwitzer, 1987). Goal setting relates to the motivational issue of what goals a person will adopt. The theories that explain entrepreneurial goal setting, the TPB (Ajzen, 1991) and the EEM (Shapero and Sokol, 1982) both posit that individuals consider the feasibility and desirability of the available choice options. Goal striving, on the other hand, entails the volitional issue of behaving with respect to set goals and thus of how a person moves most effectively toward a chosen goal (Gollwitzer, 2012). Volition concerns the translation of existing goals into action and, specifically, the regulation of these processes (Brandstätter et al., 2003).

The Rubicon model (Achtziger and Gollwitzer, 2008) identifies four action phases. The first and fourth are motivational and concerned with goal setting, and the second and third are volitional and concerned with goal striving and implementation. Each phase presents a different task to be addressed by the individual (Gollwitzer, 1990; 1999; 2012). The first of these tasks, which arises in the predecisional phase, requires individuals to decide which of their desires they really want to pursue. Once the goal intention has been formed, the second task to be solved is promoting the initiation of goal-directed action. The task facing individuals in this postdecisional (and preactional) phase is to determine how best to go about attaining the chosen goal. In this phase, actions are planned that facilitate the achievement of the chosen goals. Having formulated an action plan, the individual enters the actional phase, and faces a third task-ensuring the behaviors undertaken to achieve specific goals are successful. In the fourth phase, individuals look back at what they have achieved, and at the same time, contemplate future action (Achtziger and Gollwitzer, 2008). 
The name of the Rubicon model refers to the associated mindset theory of action phases. According to Gollwitzer $(1990 ; 2012)$, in the predecisional phase, information is processed in an open-minded, impartial manner. Once the goal intention has been established, what Gollwitzer refers to as an implemental mindset sets in, which is characterized by biased and partial processing of information on desirability and feasibility, and a reduced receptiveness (closedmindedness) to new information. The transition from the deliberative to the implementation mindset was characterized by Heckhausen and Gollwitzer (1987) as akin to crossing the Rubicon: once the goal is decided upon, it will be rigorously pursued.

In this study, we focus on the preaction and action phases. These phases are volitional in nature as they require willpower (Gollwitzer, 2001). First, we study emotions that cause people to delay actions and that can therefore place demands on volitional capacity. Second, we study volitional capacity in the form of self-control that helps to successfully accomplish goal-oriented tasks.

Figure 1 provides an overview of our research model. The hypotheses follow the action phase model, which presumes that actions start with motivation. Therefore, the effects of the avoidance-oriented emotions (doubt, fear, aversion) and also of self-control on action are not direct, but these constructs moderate the relationship between intentions and taking action.

INSERT FIG. 1 ABOUT HERE

\subsection{Action doubt, action fear, and action aversion}


Based on a review of intention-action gaps in other research domains, and the literature on procrastination, we identify action doubt, action fear, and action aversion as avoidance-oriented emotions that cause difficulties in the implementational action phases. Research on procrastination suggests that individuals tend to avoid unpleasant tasks (McCrea et al., 2008; Steel, 2007). Such tasks would include those that are too challenging, or that provoke fear, doubt, and aversion. People can also be averse to completing a task they view as feasible but consider tedious (Van Eerde, 2000). The idea that emotions such as doubt, fear and aversion may lead to procrastination is considered in several streams of literature, including the theories of approach and avoidance (Carver, 2006; Elliott, 2006), the affect-as-information theory (Schwarz and Clore, 1983; for an application to entrepreneurship see Baron, 2008), the activating and deactivating effects of particular emotions (Feldman et al., 1998; for an application to entrepreneurship see Foo et al., 2013) and promotion and prevention focus (Higgins, 1998; for an application to entrepreneurship see Brockner et al., 2004). The important issue for the current study is that these emotions place demands on an individual's volitional capacities when preparing for or implementing action. We will now provide a more detailed discussion of doubt, fear, and aversion in the context of the preactional and actional phases of the Rubicon model.

\subsubsection{Action doubt}

In the preactional phase, action plans are formulated prior to the implementation of actions. Gollwitzer (1999) notes that most people prefer to make concrete action plans only after they have formed a goal intention. Planning an action is different from forming a goal intention: Even if the goal intention was formed based on a generic perception of feasibility at the business or opportunity level, that did not necessarily entail detailed assessment of the implementation 
aspects of each separate step to start the business. At the level of specific actions, a person may be uncertain about what to do, where to start, and how to choose between different courses of action, leading to difficulties in action planning. In this study, we refer to uncertainty as an emotion — feeling uncertain — and we will use doubt as an equivalent term. We define action doubt in the context of aspiring entrepreneurs as not knowing how to embark on the start-up process, and feeling uncertain about the effects and appropriateness of alternative actions.

McMullen and Shepherd (2006) state that uncertainty in the context of action is a sense of doubt that blocks or delays action, and produces hesitancy, indecision, and procrastination (see also Frese, 2009). McKelvie et al. (2011) recently provided empirical evidence that uncertainty leads to delay. The study revealed that entrepreneurs are reluctant to act under conditions of what Milleken (1987) refers to as response uncertainty: a lack of knowledge of response options and/or an inability to predict the effects of a response choice. Response uncertainty is akin to our concept of action doubt, although in the context of acting on entrepreneurial intentions, action is self-initiated rather than a response. Gielnik et al. (2013) provide further indirect evidence that doubt leads to procrastination. They find that action knowledge acquired in a training setting is directly related to the amount of subsequent entrepreneurial action taken. In summary, we expect feelings of doubt to cause difficulties in the preactional phase, leading to implementation problems that hinder the translation of entrepreneurial intentions into actions.

Hypothesis 1a: Action doubt moderates the relationship between intention strength and taking action such that the effect of intention strength on taking action will weaken in proportion to the strength of action doubt. 


\subsubsection{Action aversion}

Even in the absence of doubt, implementation cannot be guaranteed, because further problems can arise. Aspiring entrepreneurs might for example find it difficult to action one or more of the many different activities required to set up a business because they have an aversion to doing so, in other words the required action is experienced as aversive. We define action aversion in the context of entrepreneurial action as feeling repelled by conducting particular gestation activities. People may feel aversion toward such activities as bookkeeping, researching and dealing with regulations, raising finance, and recruiting and managing employees. When forming the original intention to start a new venture, prospective entrepreneurs may have had only a rudimentary awareness of these activities (or even be unaware of them) and thus be only remotely aware of their aversion to them. However, that aversion becomes increasingly salient as the time approaches to take action.

People are prone to postponing aversive tasks to avoid the unpleasant feelings they provoke (McCrea et al., 2008; Steel, 2007; Van Eerde, 2000), and this applies to businesspeople as much as to anyone else. Moreover, when starting a new venture the prospective entrepreneur can never be certain the venture will succeed. The uncertainty of the pay-off from tackling the aversive tasks can be another reason for postponing action. In summary, we expect feelings of aversion toward one or more tasks associated with new venture creation to obstruct individuals from turning their entrepreneurial intentions into actions. 
Hypothesis 1b: Action aversion moderates the relationship between intention strength and taking action such that the effect of intention strength on taking action will weaken in proportion to the strength of the aversion felt toward that action.

\subsubsection{Action fear}

Successfully dealing with the tasks necessary in the preaction and action phases can be obstructed by yet another phenomenon. As an uncertain, risky event approaches, fear tends to increase, and the urge to back out is augmented by the tendency to think about practical considerations and the implications of loss as the moment of action draws near (Loewenstein et al., 2001). Fear may trigger automatic avoidance responses (Gable et al., 2000) and conscious reflection (Baumeister, Vohs, DeWall and Zhang, 2007), prompting questions such as, “Do I really want to give up my job?" and "Do I really want to invest a sizeable portion of my hardearned savings?" Fear also shifts the focus to the magnitude of (negative) outcomes, as opposed to their probabilities (Loewenstein et al., 2001). In the context of acting on entrepreneurial intentions, we define action fear as the experience of anxiety in relation to conducting gestation activities.

Action fear may cause individuals to postpone both the planning and execution of action. Fear can energize some aspiring entrepreneurs and propel them toward action, for example, if they fear missing an opportunity (Markman et al., 2005). However, fear of loss or failure and anticipatory feelings of regret may lead people to become more cautious when intentions are due to be turned into actions. When prospective entrepreneurs pay more attention to the potential for short-term loss accruing from risky courses of action than to potential benefits; they might 
choose to delay action. In the entrepreneurial context, Foo (2011) and Welpe et al. (2012) found that fear leads to caution and avoidance. Overall, we propose that experiencing fear in relation to conducting gestation activities can prevent an individual from turning their entrepreneurial intentions into actions.

Hypothesis 1c: Action fear moderates the relationship between intention strength and taking action such that the effect of intention strength on taking action will weaken in proportion to the strength of action fear.

\subsection{Trait self-control}

The way individuals address the tasks that must be completed in the implementational action phases is not only affected by their experience of emotions that induce avoidance, but also by their volitional capacity, for which we analyze the role of self-control (or self-discipline). Selfcontrol is the ability of individuals to alter their states and responses, including exerting control over thoughts, emotions, impulses, desires, and performance (Tangney et al., 2004). It is also considered to be the deliberate, conscious, and effortful subset of self-regulation (Baumeister, Vohs and Tice, 2007) that is central to people's ability to get along with others, and achieve goals that may require sacrifices (Ahlquist and Baumeister, 2012), as is the case with starting a new venture.

To the best of our knowledge, trait self-control has not yet been studied in the context of entrepreneurial behavior. However, research in other domains has demonstrated the benefits of strong self-control. Mischel et al. (1988) and Shoda et al. (1990) showed that children's ability to 
resist one marshmallow now for two marshmallows in the near future predicted student achievement test (SAT) scores and interpersonal success later in life. Wolfe and Johnson (1995) found that self-control was the only one of 32 personality variables that contributed significantly to the prediction of the grade point average of university students. Moreover, research found evidence for linear effects such that more self-control is better, whereas analyses designed to test for curvilinearity failed to consistently find empirical support (Tangney et al., 2004). Substantive evidence from other behavioral domains shows self-control is a strong negative predictor of procrastination (Steel, 2007).

Gollwitzer (1999) points out the many challenges of the volitional action phases that include warding off distractions, flexibly stepping up efforts in the face of difficulties, dealing with dips in motivation following failures, and negotiating conflicts between competing goals. Those with strong self-control should be better equipped to regulate these difficulties, including the deactivating effects of action doubt, fear, and aversion. Even in the absence of acute difficulties, inertia alone can prevent people from becoming active; however, inertia can be overcome by exercising self-regulatory strength (Bauer and Baumeister, 2011), the term used by Baumeister and colleagues to refer to an individual's ability to direct or control their behavior. Trait selfcontrol is regarded as a person's long-term average level of self-regulatory strength (Baumeister, Vohs and Tice, 2007). They find that self-regulatory strength becomes depleted over time when demands are made on that resource (Bauer and Baumeister, 2011; Muraven and Baumeister, 2000). Those with high levels of trait self-control start out with a higher level of self-regulatory strength, and are thus better able to take action even if there are many other demands on their volitional capacity. In summary, we expect self-control to enhance the effect of intention 
strength on taking action. As stated above, we are interested in the interaction effect as the action phase model shows that volition is preceded by motivation - it does not have motivating properties of its own.

Hypothesis 2. Trait self-control moderates the relationship between intention strength and taking action such that the effect of intention strength on taking action will be stronger when trait selfcontrol is high.

Furthermore, those with strong self-control might be expected to be less likely to experience action doubt, fear, and aversion (see Figure 1). Processes underlying the self-control of emotion (or emotion regulation) include the regulation of attention, appraisal, and response inhibition (Fox and Calkins, 2003). Particularly cognitive reappraisal, changing how we think about a situation in order to decrease its emotional impact, has been found to be a common strategy to down-regulate negative emotions and represents what emotions researchers call a antecedentfocused strategy: it takes place before the emotion response tendency has become fully activated (Gross, 2002; Gross, Richards and John, 2006). The regulation of attention and the reframing of meaning are also strategies outlined by the so-called hot/cold theory of self-control (Metcalfe and Mischel, 1999), which suggests that those with greater self-control are guided by 'cold' cognition rather than 'hot' emotion. As a consequence of using these strategies, those high in self-control experience de-activating emotions at lower levels of intensity, or not at all. In sum, we hypothesize: 
Hypothesis 3. Trait self-control will have a negative effect on the extent of a) action doubt, b) action aversion, and $\mathbf{c}$ ) action fear as experienced by aspiring entrepreneurs.

\section{Data and methods}

\subsection{Data}

We utilize data from a survey of the entrepreneurship-related opinions, attitudes, and behaviors of the general adult population (of 20-64 years old) in Finland. The data were collected in two waves 12 months apart in 2011 and 2012. The survey instruments for both waves were distributed to a convenience sample of test subjects of different ages and from different backgrounds, and the questionnaires were improved based on the feedback received. Additionally, before launching the survey, we conducted a pilot test of the wave-1 survey instrument, sending out 1,000 questionnaires to a random sample of adults (achieving a response rate of $20 \%)$.

In wave 1, we extracted a sample of 10,000 individual postal addresses from the Finnish Population Register Center. The list of 10,000 individuals is representative of the target population of 20-64 year old adults in terms of sex and age, and weighted by the population sizes of the municipalities chosen for the sample. Instead of simple random sampling, we selected 38 municipalities in consultation with statisticians at the Population Register Center. The strategy was designed particularly to avoid the problem of over-representing the capital region of Greater Helsinki, which would have occurred in simple random sampling. Furthermore, a representative sample of municipalities accounts for regional variations in the 
rates of enterprising activity. The postal survey produced 2,263 responses, representing a response rate of $23 \%$. The response rates range from $14 \%$ to $31 \%$ in the 38 municipalities with a standard deviation of 3.7 percentage points. Within the urban, semi-urban, and rural types of municipalities, the response rates range from $22 \%$ to $24 \%$.

Examination for potential nonresponse bias by means of archival and wave analysis (Rogelberg and Stanton, 2007) did not indicate notable age-based or regional bias between early and late return mailings, or when comparing the sample to the respective population values. Moreover, these analyses did not point to significant differences in the mean of intention strength between early and late respondents.

From the initial sample of 2,263 respondents, 1,002 qualified for inclusion in wave 2. Because the purpose of the study is to examine the translation of entrepreneurial intentions into actions, we excluded those who were already either self-employed or engaged in business gestation activities in wave 1 (18\% or 407 individuals). A further 279 cases had to be excluded due to an excessive number of missing values or otherwise unusable responses, and 575 respondents chose not to contribute to wave 2 when (to meet research ethics requirements) we asked for permission to contact them again for wave 2. We compared the sample of the remaining 1,002 respondents with the sample of 1,856 eligible respondents for wave 2 (i.e., $n=2,263$ less the 407 individuals who were already self-employed or nascent entrepreneurs). We did not find notable demographic differences between these two samples. We received 703 responses in wave 2 , representing a response rate of $70 \%$. In order to test our hypotheses pertaining to the translation of entrepreneurial intentions into actions, we focus on those individuals in the longitudinal sample 
who had positive entrepreneurial intentions (intention $>1$ on a scale of 1 to 6 where a score of 1 indicates no intention at all to engage in start-up activities in the next 12 months) in wave 1 $(n=170$,$) and whose survey responses did not contain an excessive number of missing responses$ to the key variables in wave $2(n=161)$.

\subsection{Measures}

\subsubsection{Intention and action}

The dependent variable (taking action to start a new venture) and the principal predictor (intention strength) were operationalized in accordance with Ajzen's (2011/2014) instructions for developing intention and action measures, in that the measurement items for intention and action were matched with respect to the target behavior and time frame.

The target behavior is defined as actions taken with the aim of starting a business. This choice was based on previous research practice in studies of intention and action relating to goals that are similar to new venture creation, in the sense that they comprise multiple behaviors. An example is finding employment (Caska, 1998; Van Hooft et al., 2004), where researchers record the actions undertaken in search of employment, not whether employment was found. Therefore, the intention items refer to engaging in activities to start a new venture, whereas the outcome variable captures the amount of action taken, rather than whether a venture was established.

Moreover, all intention and action items refer to a 12-month period. Thus, the intention items refer to taking steps to start a new venture in the forthcoming 12 months (sample item: "I intend to take steps to start a business in the next 12 months"), and subsequent actions were assessed 
after those 12 months had passed (sample item: "In the last 12 months, how much effort have you put into activities to facilitate starting a business?"). The twelve-month time frame was deemed a good compromise between not letting too much time elapse between intentions and actions, so as to ensure that it was the same intention from wave 1 whose effect was picked up in wave 2, and not using too short a time frame within which start-up intentions are unlikely to be acted upon. All items were measured using 6-point rating scales. Appendix A displays a full list of the measurement items used in this analysis.

\subsubsection{Action aversion, fear, and doubt}

We developed a set of items to capture action aversion (sample item: "There were tasks associated with starting my intended business that felt aversive to me"), action fear (sample item: "The thought of actually taking steps to start my intended business scared me"), and action doubt (sample item: "It was unclear to me what actions are required to start a business"). The introductory question leading to these items referred to having experienced these emotions in the context of new venture creation in the 12 months following wave 1 . Prior to launching wave 2 , we tested the initial scales with a small convenience sample of university students in order to develop a preliminary understanding of the psychometric properties of the scales. Based on these tentative analyses, we amended the sets of items and compiled efficient scales for inclusion in wave 2 (Appendix A).

\subsubsection{Trait self-control}

The measure for trait self-control included in the wave-1 survey was the 13 -item version of the self-control measure in Tangney et al. (2004) (Brief Self-Control Scale, BSCS), which was 
reported to have good psychometric properties. A sample item from the scale: "I am good at resisting temptations."

\subsubsection{Control variables}

Our model specifications include a number of control variables to avoid over- or underestimating the effects of the variables of interest due to omitted variable bias. Each of the control variables included was expected to correlate with the dependent variable (taking action) and one or more of the independent variables. It was also expected that it would not mediate the effect of any independent variable on the dependent variable.

The first control variable is a gender dummy (with female coded as 1). Previous research indicates that women have a lower entrepreneurial propensity than men (e.g., Xavier et al., 2012) and also exhibit a lower level of entrepreneurial intention (Schlaegel and Koenig, 2014). Moreover, studies in other fields have shown procrastination to be weakly associated with being male (e.g., Steel, 2007). Therefore, we can expect gender to correlate with taking action, intention strength, and the action-level emotions that are hypothesized to cause procrastination.

The second control variable is age (in years), which we include in a quadratic specification to account for the inverse U-shaped effect of aging on new venture creation (Lévesque and Minniti, 2006). Econometric evidence suggests that age is one of the most important determinants of entrepreneurship, which is why we expected it to be a significant determinant of taking action in our study. Meta-analytic evidence also shows that age is significantly correlated with the level of entrepreneurial intention (Schlaegel and Koenig, 2014), which is represented by intention 
strength in our model. Furthermore, studies in other fields have shown that older people are less likely to procrastinate (Steel, 2007). Therefore, we also expect age to correlate with the actionlevel emotions.

The third control variable is a dummy indicating whether the respondent had prior entrepreneurial experience. This is defined as the individual having started and run one or more businesses prior to the time of the wave-1 survey, but not being engaged in entrepreneurial activity at that time. In this analysis, entrepreneurial experience constitutes a measure of past behavior, which meta-analytic evidence from applications of the TPB shows is significantly correlated with both intention and action (Conner and Armitage, 1998). Moreover, entrepreneurial experience is conceptually related to action doubt, fear, and aversion, as those with experience are less likely to be adversely affected by these conditions. Therefore, entrepreneurial experience could be expected to correlate with the action-level emotions.

Finally, wave 2 included two variables that captured reasons to intentionally postpone acting on entrepreneurial intentions: saving money and/or accumulating experience before commencing start-up activities, and unexpected changes in the work or life situation (both measured on a six-point rating scale). Saving money (Quadrini, 2002) and accumulating experience (Parker, 2009; Rotefoss and Kolvereid, 2005) have been shown to correlate with entrepreneurial intention and action. As intentions are formed and translated into action with expectations about the future in mind, unexpected changes in individual work or life situations can correlate with entrepreneurial intentions and actions (Chiles et al., 2007). 


\subsection{Factor analysis and assessment of common method bias}

Before computing index scores by averaging the item scores for each multi-item measurement scale, the scales were subjected to a confirmatory factor analysis (CFA). The results generated through maximum-likelihood estimation show that all items loaded on their intended factors at the $.1 \%$ significance level and the fit indices suggested an acceptable fit between the model and the data (Hu and Bentler, 1999): the comparative fit index (CFI) score of .93 was close to the recommended threshold of .95; and the root mean square error of approximation (RMSEA) and the standardized root mean squared residual (SRMR) scores of .052 and .066 were below the recommended maximums of .06 and .08 , respectively.

The model shows good discriminant validity: the model specification where all items load on their intended factors results in a superior fit compared to any alternative specification that we tested, such as allowing all items collected in either survey wave to load on a single factor. The Cronbach's alpha coefficients for the constructs range from .73 to .92 (Table 1), thus consistently exceeding the conventional threshold of .70 and indicating good internal consistency (Nunnally, 1978).

Given the moderately high correlations between the three action-related emotions (Table 1), we estimated CFA models separately for these constructs. A model where the items representing each construct load on their own factors (CFI: .99; RMSEA: .052; SRMR: .030) was compared with model specifications where any two or all three sets of items load on a single factor. The three-factor model had a significantly better fit with the data than any of the alternative 
specifications: the differences in the chi-squared fit statistic were in the range of 31.3 to 129.3 with two or three degrees of freedom (always $p<.001$ ).

Common method bias (CMB), or false conclusions resulting from "variance that is attributable to the measurement method rather than to the constructs the measures represent" (Podsakoff et al., 2003, p. 879), is often cited as a risk in cross-sectional survey studies. It particularly affects studies relying on data consisting of cognitive measures collected in self-report surveys (Harrison et al., 1996). If methodological triangulation is not possible, Podsakoff et al. (2003) recommend a range of ex ante and ex post measures to reduce the risk of CMB. However, Spector (2006) argues (and Richardson et al. (2009) provide impressive evidence supporting the point) that ex post measures to assess data for $\mathrm{CMB}$ are unreliable and often misleading. Therefore, we adopted the ex ante CMB reduction strategies recommended by Podsakoff et al. (2003). In addition to protecting the anonymity of the respondents to reduce evaluation apprehension, and counterbalancing the question order in the questionnaire (Podsakoff et al., 2003), we collected data at two different points in time (Chang et al., 2010). We believe that these measures, especially splitting the data collection into two waves 12 months apart, significantly reduce the risk of CMB affecting our conclusions.

\subsection{Descriptive statistics}

Table 1 presents the means, standard deviations, and Pearson correlation coefficients for all variables. For the multi-item indices, Table 1 also displays the Cronbach's alpha scores. Of the 161 respondents (all of whom reported a positive level of intention to engage in activities to start a business in wave 1), 27\% (43 individuals) did not take any action. If we define lack of action as 
"taking no or very little action," then $69 \%$ had not taken action, which highlights the importance of scrutinizing the intention-action gap.

\section{INSERT TABLE 1 ABOUT HERE}

\section{Results}

\subsection{Direct effects}

We applied path analysis with the maximum-likelihood estimator to test the hypotheses. Path analysis was chosen over linear regression analysis because our research model includes multiple dependent variables (Fig. 1), and path analysis permits the testing of all these relationships in a single model. Moreover, we deemed path analysis more appropriate than a fully-fledged structural equation model because it optimizes sample size relative to the parameter estimates. In other words, path analysis allows us to model the full complexity of the relationships depicted in Figure 1 while at the same time keeping the number of estimated parameters reasonable for the sample size of 161 observations. All continuous variables are $z$-standardized (mean 0 , standard deviation 1) throughout the analysis. Hence, all results are expressed in units of standard deviation.

Table 2 presents four specifications of the path model. Model 1 includes only the control variables; Model 2 adds the direct effects of the independent variables; Model 3 adds the interaction terms for testing hypothesis 1 ; and Model 4 adds the interaction term for testing hypothesis 2 . In addition to serving as the baseline model for the interaction tests, Model 2 permits an examination of hypothesis 3 , which proposed that trait self-control exerts a negative 
effect on action aversion, fear, and doubt. The results support this hypothesis, as the path coefficient of trait self-control is consistently negative and statistically significant in the equations pertaining to each of the three emotions.

\section{INSERT TABLE 2 ABOUT HERE}

\subsection{Moderation effects}

Model 3 in Table 2 adds the interactions between the three emotions and intention strength to the model specification. An examination of the product terms shows that the effect of intention strength on taking action is positively dependent on the level of action aversion, and negatively dependent on the level of action doubt. The product coefficient of the interaction of action fear and intention strength is nonsignificant, and hypothesis $1 \mathrm{c}$ is therefore not supported. In order to facilitate further interpretation of the significant interactions, we computed the simple intercepts and simple slopes for intention strength (Aiken and West, 1991) by letting the emotions vary one at a time (-1 SD and +1 SD) while holding all the other variables at their means (Preacher, 2014). The results are graphically illustrated in Figures 2 and 3. The simple slopes and their significance tests are provided in the footnotes to the figures.

INSERT FIG. 2 ABOUT HERE

INSERT FIG. 3 ABOUT HERE

Contrary to hypothesis $1 \mathrm{~b}$, the effect of intention strength on taking action is stronger when action aversion is at a high level (Fig. 2). In fact, at a low level of action aversion, the effect of 
intention strength is not even statistically significant. Therefore, hypothesis $1 \mathrm{~b}$ is not supported. On the other hand, the effect of action doubt supports hypothesis 1a: the effect of intention strength on taking action is positive and significant when action doubt is low, but it is not significant when action doubt is high (see Figure 3).

Model 4 in Table 2 adds another interaction term to the model specification; the interaction between trait self-control and intention strength, which relates to hypothesis 2 . The product term is positive and significant, indicating that the effect of intention strength on taking action is positively dependent on the level of trait self-control. Again, we computed and plotted the simple slopes to facilitate interpretation (Fig. 4). The effect of intention strength on taking action is positive and significant when trait self-control is high, whereas it is not significant when trait self-control is low. Therefore, hypothesis 2 is supported.

\section{INSERT FIG. 4 ABOUT HERE}

\subsection{Robustness tests}

We conducted a number of further tests to examine the robustness of our findings. One set of tests explored the potential ameliorating effect of trait self-control on the relationships between

the action-level emotions, intention strength, and taking action. It is logical that individuals with high levels of trait self-control would deal more effectively with volitionally demanding conditions than those with low levels of self-control. Therefore, we examined whether the hypothesized interaction effects (hypothesis 1a-c) are conditional on the volitional capacities of the prospective entrepreneurs, which are captured by the construct of trait self-control. Using 
Model 4 in Table 2 as the baseline, we added interactions between the action-level emotions, self-control and intention strength to the model. However, the higher-order interaction term proved to be nonsignificant in each case, which is why we did not explore this idea further.

Although our theorizing argues against a mediation effect (i.e., the emotions mediating the effect of trait self-control on taking action), we nevertheless examined this possibility in order to ascertain that the emotions really have a moderating, rather than a mediating role in the model. The result is very clear: the indirect effect of trait self-control is nonsignificant, even when the possibility of a moderated mediation is accounted for (Appendix B).

Another set of robustness tests pertained to our intention measure. Even though intention was operationalized following Ajzen (2011/2014), it could be argued that the items using the words "I plan..." and "I will try..." do not capture the essence of intention. Therefore, we estimated Models 2-4 in Table 2 using "I intend to take steps to start a new business in the next 12 months" as the sole intention measure. The substantive results were the same as reported above. The only notable difference being that the level of significance of the interaction terms Aver*IS and Doubt*IS in Models 3 and 4 was higher (1\% instead of 5\%) when the single-item intention measure was used. Therefore, our results are robust against different specifications of the intention measure.

Although the modest inter-correlations between the independent variables (Table 1) do not suggest multicollinearity would be a problem in our analysis, we nevertheless conducted further tests to ensure the conclusion was robust (Williams, 2014). First, we computed the variance 
inflation factor (VIF) scores for each equation in Table 2. The mean VIF score across the equations ranges from 1.04 to 1.53 . The highest individual VIF scores are found in the equation pertaining to taking action in Model 4 (Table 2), where the interaction product coefficients have VIF values ranging from 1.26 to 2.50 . Although a VIF value of 2.5 is relatively high, it pertains to an interaction coefficient whose constituent elements are also part of the model. Moreover, there are only minor changes in the non-interaction coefficients between Models 4 (including all interaction terms) and 2 (including no interaction terms), which suggests that the interaction term does not cause multicollinearity that influences the effects of the other variables in the model. The highest VIF without interactions included (Model 2) is 1.82, which suggests that multicollinearity is not a serious concern in our analysis. We also examined the correlations between the coefficients and found them to be modest: only one correlation exceeded .40 and this was a correlation between two interaction terms (coefficient: -.52). Finally, we performed the condition number test and the highest score among all the equations was 3.96, which is clearly below the informal rule of thumb of 15 indicating multicollinearity would be a concern.

Finally, we examined the sensitivity of the interactions in Table 2 for different model specifications. We included the product terms one by one in the model, with different combinations of the control variables. This exercise revealed that although the interactions of intention strength with trait self-control and action doubt seem robust, the significance of the product term Aver*IS appeared to be dependent on the inclusion of $D o u b t^{*} I S$ in the model. This points to the potential existence of a higher-order interaction effect. To investigate this aspect, we estimated another path model that added the interaction between action aversion, action doubt, and intention strength to Model 4 in Table 2. The estimates in Table 3 show that the 
higher-order interaction term is statistically significant. This, in turn, suggests that the moderating effects of action doubt and action aversion are not independent of each other. The plot of the interaction in Figure 5 suggests that the effect of intention strength on taking action is strongest when action aversion is high and action doubt is low. The simple slope for this particular combination differs from those of the remaining combinations of aversion and doubt with statistical significance, whereas the differences between the other three simple slopes are not significant.

INSERT TABLE 3 ABOUT HERE

INSERT FIG. 5 ABOUT HERE

Table 4 provides a summary of the results on each hypothesis, taking into account the additional information from the sensitivity analysis.

\section{INSERT TABLE 4 ABOUT HERE}

\section{Discussion}

This study contributes to understanding the relationship between intentions and actions in entrepreneurship. To date, research employing intention models of entrepreneurial behavior has almost exclusively focused on explaining intention, paying little attention to investigating whether intentions lead to actions to establish a business (Schlaegel and Koenig, 2014). However, over two-thirds of the 161 people in our sample who expressed an intention to engage in such activities within a year in 2011 took few or no steps toward starting a new venture in the 
following 12 months. This finding questions the value of exclusively focusing on intentions: apparently, there are factors other than intention involved in distinguishing those who take action from those who do not. The main implication of our study is that the intention-action relationship is better understood if volitional aspects are taken into account.

\subsection{Trait self-control}

One main finding concerns the important role of self-control. The results indicate that selfcontrol is neither a direct predictor of whether entrepreneurial action will be taken, and nor does it correlate significantly with intention strength. Thus, it has no motivating properties by itself; however, self-control does help bring intentions to fruition. A principal role of self-control is to counter demands on volitional capacity: a person exercising strong self-control is less likely to be adversely affected by action doubt, action fear, and action aversion. Moreover, the intentionaction relationship is conditional on the level of self-control, such that the effect of intention strength on taking action is stronger at higher levels of self-control. For those with lower levels of self-control, the entrepreneurial intention has the characteristics of a wish as it has no regulatory power over behavior (Frese, 2007). The sizeable intention-action gap suggests that for many, entrepreneurial intentions are perhaps not that different from other aspirations, such as visiting another part of the world, learning a foreign language, or learning to play a musical instrument. In other words, it seems that for some people, having an entrepreneurial intention is attractive as long as executing it remains in the future. Executing such entrepreneurial intentions requires that the individual possess the volitional capacities to turn plans into reality. 
Given the findings on the strong effect of trait self-control on performance in other fields (Duckworth and Seligman, 2005; Mischel et al., 1988; Tangney et al., 2004), it is somewhat surprising that entrepreneurship scholars have not yet studied its importance. To the best of our knowledge, our study is the first to examine the effects of self-control in an entrepreneurial context. Our results indicate that taking action in relation to an opportunity depends strongly on the ability to regulate one's own behavior.

\subsection{Action aversion, action doubt, and action fear}

Another set of findings concerns the effects on the intention-action relationship of experiencing the three emotions that were hypothesized to hinder activity: action aversion, action fear, and action doubt. This study thus responds to calls by Foo et al. (2009) to study the de-activating effects of specific emotions, and by Foo et al. (2013) to study the different action tendencies and actual behaviors implemented in response to the emotions experienced. We find that the experience of doubt at the action level hinders the translation of intentions into actions. This supports McMullen and Shepherd's (2006) argument that doubt in the context of entrepreneurial action produces hesitancy, promotes indecision, and encourages procrastination.

In contrast to the effect of doubt arising from uncertainty, we did not find action fear and action aversion to be negative moderators of the intention-action relationship. Although Welpe et al. (2012) and Foo (2011) found that fear led to avoidance, we did not find such an effect. We did find that a high level of self-control suppresses action fear. Given the strong evidence for the facilitating role of self-control, it may be self-control that explains the finding reported in metaanalytical work (Rauch and Frese, 2007; Stewart and Roth, 2001) that entrepreneurs are 
somewhat less risk averse than non-entrepreneurs-perhaps they are good at managing the feelings associated with taking risks.

With regard to action aversion, we found the opposite effect to that expected, namely that those who experience action aversion are more likely to have taken action, particularly when experiencing little action doubt. One explanation is that action aversion may be anticipated but also experienced when the action is taken. For example, a person makes an effort to undertake customer validation, and receives negative feedback, making the customer validation task an aversive experience. The action-level emotions were reported in retrospect, rather than predicted beforehand. Thus, it may be the case that those who took more action were more likely to find certain gestation activities unpleasant. Yet another possibility is that aversion does arise before action, and that this negative emotion inspires people to try harder. This would be in line with the mindset theory associated with the Rubicon model of action phases, which states that once people arrive at the volitional action phases, they are in an implemental mindset, which increases the will and determination to do things, even in the face of adversity. This might have been the case with action aversion.

A similar line of reasoning is offered by Foo et al. (2009) referencing control theory (Carver and Scheier, 1981), which posits that if people are on track in terms of goal achievement, they are liable to cruise, and if they are lagging behind, they increase their efforts. Indeed Foo et al. (2009) found that negative emotion led to increased effort on tasks requiring immediate action (positive emotion had the same effect for next-day outcomes). However, the participants in their study were committed residents of an incubator scheme with clear deadlines: a setting quite 
different from that of the average participant in our study. Moreover, control theory fails to explain how $69 \%$ of our sample took little or no action, as these people were behind schedule and therefore should have been experiencing negative emotions, prompting them to try harder (Scholer and Higgins, 2013). Finally, the assertion that negative emotion leads to an increase in effort contradicts the robust finding from procrastination studies that people are put off by tasks they find unpleasant (Steel, 2007). The divergence of findings with respect to action doubt, fear, and aversion moderating the intention-action relationship suggests that different dynamics characterize these relationships. A research design that includes more data collection moments might be able to establish whether action aversion prevents continued action, rather than the initiation of action.

\subsection{Implications for theory and future research directions}

The results of this study hold a number of implications for theory. They confirm it makes sense to distinguish motivational and volitional action phases. However, they do not align entirely with the mindset notions that are associated with the phases. According to Gollwitzer $(1990 ; 2012)$, in the predecisional phase people have a deliberative mindset, which is characterized by an accurate and impartial analysis of desirability and feasibility-related information and by a heightened general receptiveness to available information. Once a decision has been made and a goal intention has been formed, the implementation mindset sets in, which is characterized by cognitive tuning toward implementation-related thoughts and information, by an overly optimistic analysis of feasibility-related information, and a partial analysis of desirability-related information, and by a comparatively reduced receptiveness (closed-mindedness) to available information. The transition from the deliberative to the implementation mindset has been 
characterized by Heckhausen and Gollwitzer (1987) as akin to crossing the Rubicon: once the goal has been decided upon, it will be rigorously pursued.

The results of the current research suggest an alternative pattern: the goal or intentions may have been formulated based on partial, incomplete, and inaccurate information, and the implementation phase serves to align those original ideas with reality. This reality check prevents many intenders from taking action, unless they have the self-discipline to overcome difficulties. It seems that many intenders never cross the Rubicon, in spite of having formed goal intentions. In our study, this is particularly the case for those experiencing action doubt. In our opinion, the difference between our case of entrepreneurial intentions and the experimental evidence cited by Gollwitzer and colleagues is commitment: once committed, people cross the Rubicon, but many intenders remain relatively uncommitted (see also Achtziger and Gollwitzer, 2008). We therefore recommend future studies use measures of commitment as an additional construct that influences whether intentions are translated into actions or not.

An alternative theory with potential to explain the intention-action gap is construal level theory (CLT). CLT proposes that temporal distance changes how people respond to future events and activities by changing the way they mentally construct those events and activities (Trope and Liberman, 2003; 2010). The greater the temporal distance, the more likely events are to be represented in terms of a few abstract or general considerations that convey the perceived essence of the events (high-level construals). In contrast, construals for the short term are based far more on concrete, incidental, and context-dependent considerations (i.e., are low-level construals). Ordinarily, people have less information on events in the distant future than on those 
in the near future, and are therefore likely to make less accurate predictions about the former. Moreover, CLT-based studies show that high-level construals are largely based on desirability concerns, reflecting ideals, whereas feasibility and cost concerns are dominant in low-level construals (Eyal et al., 2004; Trope and Liberman, 2010). Our results suggest that intentions in entrepreneurship research are often framed as high-level construals: relatively abstract and generic assessments of the desirability and feasibility of the venture, with desirability typically given greater weight than feasibility. A CLT-based study in the entrepreneurship domain confirms CLT's predictions: it found desirability exerted a stronger influence on opportunity evaluation when the exploitation phase is temporally distant rather than close, whereas feasibility affects evaluation more strongly when exploitation is close rather than distant (Tumasjan et al., 2013). With intentions being construed in rudimentary, aggregate terms based on desirability concerns, people can easily encounter implementation problems at the time of action. Future research might operationalize CLT in the context of entrepreneurial intentions.

The current study also has implications for the use of the theory of planned behavior (TPB) (Ajzen, 1991; 2011/2014) in studies of entrepreneurial intentions and behavior. Thus far, with only a few exceptions, the TPB has been employed to predict intentions, not behavior. In the TPB, behavior is predicted from intention. However, our results show that there is a sizeable group of people for whom intentions have little predictive value. A second construct in the TPB that predicts behavior is perceived behavioral control (PBC). PBC predicts both intentions and behavior - in the latter case serving as a proxy for actual behavioral control. Our results suggest that perceived and actual PBC may very well diverge, because of a divergence of time frame and level of analysis between intention formation and action. Obviously, proponents of the TPB are 
also aware of intention-behavior gaps, and have made various attempts to explain them, for example, citing hypothetical bias (Ajzen et al., 2004), and the violation of compatibility principles (Ajzen and Sexton, 1999). When using the TPB to study the emergence of entrepreneurial actions, we recommend studying additional action level constructs that moderate the intention-action relationship. A construct measuring volition such as self-control is one example, and implementation intentions (Gollwitzer, 1999) offer another avenue to operationalize intentions at the action level, by asking when, where, and how specific actions will be performed. Again, commitment is a construct that warrants consideration, as suggested by Ajzen et al. (2009, p. 1359): "It can be argued that equally favorable intentions may be accompanied by different degrees of commitment to the intended action, and that a heightened sense of commitment increases the likelihood that the behavior will be carried out." Another suggestion would be to include a measure of the preference for learning by doing and experimentation as a moderator in these research designs.

A further direction for future research might be to explore the relationship between volitional constructs like self-control, and positive emotions, particularly emotions capable of spurring action, such as entrepreneurial passion. Tangney et al. (2004) show that the effects of self-control on a variety of desired outcomes are linear, whereas Baron and colleagues demonstrate that the beneficial effects of positive affect evaporate beyond a certain optimal point (Baron et al., 2011; Baron et al., 2012). One explanatory hypothesis might be that under conditions of high selfcontrol, the inflection point moves outward. In other words, for those with high levels of selfdiscipline, being very excited and enthusiastic about an entrepreneurial opportunity plays a positive role in terms of effective pursuit of the new venture, whereas for those who are very 
excited yet have low levels of self-discipline, their excitement may not translate into tangible actions.

Another possible future research area might involve investigating whether self-control has any negative effects. For example, those with strong self-control may have more rigid perspectives, and see or seize fewer opportunities than highly impulsive people would. Impulsiveness has proven to be a predictor of procrastination (Steel, 2007). However, in the context of nascent entrepreneurship, impulsiveness may be positively related to progressing the establishment of the new venture. Our suggestion is that impulsiveness may be related to entrepreneurial intentions (a person sees an opportunity and becomes very enthusiastic about it), but self-control is required to act effectively on the business idea, whether this results in an operational business, or a decision to discontinue the start-up process.

\subsection{Practical implications}

The finding that the implementation of entrepreneurial intentions depends on self-control is important for potential entrepreneurs, who should assess whether they possess the self-discipline required to undertake entrepreneurial action. Because self-control is relatively easily observed or otherwise assessed, our findings should also be of great interest to investors and other stakeholders in new ventures. Self-control on the part of an entrepreneur can boost stakeholders' confidence in the entrepreneur's ability to run the business successfully.

Moreover, whereas in this study self-control is viewed as a trait that is relatively stable over time and place, recent research by Baumeister and colleagues shows that self-control depends on 
having access to an energy source they term self-regulatory strength. Their studies show that not only can self-control be trained, its benefits are not limited to the domain in which it was trained (Bauer and Baumeister, 2011; Baumeister et al., 2006). This suggests the intriguing possibility that one can train self-regulatory strength in a domain unrelated to entrepreneurship, yet deploy that enhanced self-regulatory strength to the advantage of an entrepreneurial venture.

A second main finding of this study is that the experience of doubt at the action level hinders the translation of intentions into actions. This suggests that many entrepreneurs could benefit from intervention programs such as that run by Gielnik et al. (2013), who report that their training in entrepreneurial action regulation is positively related to taking action. Their remedies for action doubt include training in knowing what do to (action knowledge), and in how to take action (action planning), an approach that has also been successfully applied to reduce the intentionaction gap in other fields, such as health (Schwarzer, 2008).

\subsection{Limitations}

One limitation of our study is that our dataset is formed of only two waves of data collected within a one-year time span. This limits the analysis of causality, especially regarding action doubt, fear, and aversion. Ideally, future studies investigating the dynamics of these emotions and action would collect multiple waves of data using shorter time-intervals. This would enable researchers to capture the emotions closer to the time they are encountered, and the dynamic relations between intentions, emotions, and taking action. A multiple-wave design would also be less sensitive to Type II errors than a two-wave design. There is a lower level of risk in concluding that a person has not taken action if no action has been reported for the single period 
under consideration in a multi-wave design. Moreover it would allow researchers to study patterns of taking action. Another limitation is the focus of the current research on psychological variables at the expense of others, such as economic factors. Accordingly, this study could not incorporate any assessment of the relative importance of psychological variables vis-à-vis other factors explaining the intention-action gap in the creation of new ventures. This is something that we will have to leave future research to redress.

A further notable limitation is the relatively small sample size. It is possible that we may have detected more significant interaction effects with a larger sample, and future studies should endeavor to collect a larger number of observations when investigating the intention-action gap. However, as our study shows, this is not as easy as it might appear: sending out 10,000 questionnaires resulted in a useful sample of 161 individuals for the present analysis, even though our response rates were fairly high $(23 \%$ in wave $1 ; 70 \%$ in wave 2$)$. Therefore, researchers would be advised to take the low hit rate into account when designing future studies on the topic.

The current research demonstrates the importance of volition as an explanation of the intentionaction gap in entrepreneurship. As such, this study and the ideas for future research suggested above represent a starting point for a stream of research that could help entrepreneurship research look beyond decision making to explore the actions that make entrepreneurship possible. 


\section{Appendix A. Measurement scale items}

Variable (all measured on a 6-point Likert-style scale; (R) indicates reverse coding)

\section{Intention (first wave)}

("How well do the following statements describe you?")

I plan to take steps to start a business in the next 12 months

I intend to take steps to start a business in the next 12 months

I will try to take steps to start a business in the next 12 months

Taking action (second wave)

("Please assess")

In the last 12 months, how much effort have you put into activities to facilitate starting a business?

In the last 12 months, how much time have you invested in activities to facilitate starting a business?

In the last 12 months, how much money have you invested in activities to facilitate starting a business?

Action doubt, action fear and action aversion (second wave)

("How well do the following statements describe your idea to take steps to start a business in the last 12 months?")

\section{Action doubt}

It was unclear to me what actions are required to start a business

I did not know how I would have started to set up a business

I was uncertain about what I should do to start my intended business

Action fear

The thought of actually taking steps to start my intended business scared me

I was afraid that my intended business would make a loss

Action aversion

There were tasks associated with starting my intended business that felt aversive to me

I did not like certain tasks associated with starting my intended business (e.g., bookkeeping, taxation, bureaucracy)

Some of the tasks associated with starting my intended business seemed boring to me

Trait self-control (first wave)

("How well do the following statements describe you as you normally are?")

I am good at resisting temptation

It is difficult for me to get rid of bad habits (R)

I am lazy (R)

I say inappropriate things $(\mathrm{R})$

I do things that are bad for me if they are fun (R)

I should have more self-discipline (R)

I abstain from things that are bad for me 
People think I have iron self-discipline

Pleasant and fun things sometimes prevent me from getting work done (R)

I have difficulties concentrating $(\mathrm{R})$

I can work effectively to reach long-term objectives

Sometimes I cannot prevent myself doing things I know are wrong $(\mathrm{R})$

I often act without closely considering the alternatives $(\mathrm{R})$

\section{Appendix B. Moderated mediation: indirect effects of trait self-control on taking action}

\begin{tabular}{lccccccccc}
\hline Mediator & \multicolumn{3}{c}{ (1) Action fear } & (2) Action aversion & \multicolumn{2}{c}{ (3) Action doubt } \\
\hline Moderator 1 $\rightarrow$ & \multicolumn{3}{c}{ Trait self-control } & \multicolumn{2}{c}{ Trait self-control } & & Trait self-control \\
Moderator 2 $\downarrow$ & Low & Mean & High & Low & Mean & High & Low & Mean & High \\
\hline Intention strength & & & & & & & & & \\
Low & -.04 & -.02 & -.00 & .00 & .01 & .01 & .02 & .03 & .05 \\
Mean & -.03 & -.02 & -.02 & -.01 & -.00 & .00 & .03 & $.04 *$ & .05 \\
High & -.02 & -.03 & -.03 & -.02 & .01 & -.01 & .04 & .05 & .05 \\
\hline
\end{tabular}

Notes: * denotes statistical significance at the 5\% level (one-tailed). Low is defined as $1 \mathrm{SD}$ unit below sample mean, and high as $1 \mathrm{SD}$ unit above sample mean.

The moderated mediating effect is computed based on the following two equations (intercepts and error terms omitted for simplicity): 1) Emotion $=\beta a S C+\beta$ contCONTROLS and 2) Action $=\beta_{1}$ Emotion $+\beta_{2} S C+\beta_{3} I S+$ $\beta_{4}$ Emotion $* S C+\beta_{5} S C * I S+\beta_{6}$ Emotion $* I S+\beta_{7}$ Emotion $* S C * I S+\beta_{8}$ CONTROLS. Here, Emotion denotes the focal action-level emotion, $S C$ trait self-control, IS intention strength and CONTROLS is a vector of control variables. Deriving from these equations, the moderated indirect effect of trait self-control on taking action via any one of the three emotions becomes (Hayes, 2013): $\beta a\left(\beta_{1}+\beta_{4} S C+\beta_{6} I S+\beta_{7} S C^{*} I S\right)$. 


\section{References}

Achtziger, A., Gollwitzer, P.M., 2008. Motivation and volition during the course of action, in: Heckhausen, J., Heckhausen, H. (Eds.), Motivation and Action. Cambridge University Press, Cambridge, pp. 272-295.

Ahlquist, J., Baumeister, R.F., 2012. Self-control: limited resources and extensive benefits. WIREs Cognitive Science, 3, 419-423.

Aiken, L.S., West, S.G., 1991. Multiple Regression: Testing and Interpreting Interactions, Sage, Thousand Oaks.

Ajzen, I., 1991. The theory of planned behaviour. Organizational Behaviour and Human Decision Processes, 50, 179-211.

Ajzen, I., 2011/2014. Theory of planned behavior. Retrieved from: http://people.umass.edu/aizen/tpb.html (first accessed 23 May 2011, last accessed 17 April 2014).

Ajzen, I., Brown, T.C., Carvajal, F., 2004. Explaining the discrepancy between intentions and actions: The case of hypothetical bias in contingent valuation. Personality and Social Psychology Bulletin, 30, 1108-1121.

Ajzen, I., Czasch, C., Flood, M.G., 2009. From intentions to behavior: Implementation intention, commitment, and conscientiousness. Journal of Applied Social Psychology, 39, 13561372.

Ajzen, I., Sexton, J., 1999. Depth of processing, belief congruence, and attitude-behavior correspondence, in: Chaiken, S., Trope, Y. (Eds.), Dual-Process Theories in Social Psychology. Guilford Press, New York, pp. 117-138. 
Baron, R.A., 2008. The role of affect in the entrepreneurial process. Academy of Management Review, 33, 328-340.

Baron, R.A., Hmieleski, K.M., Henry, R.A., 2012. Entrepreneurs' dispositional positive affect: The potential benefits - and potential costs - of being "up". Journal of Business Venturing, $27,310-324$.

Baron, R.A., Tang, J., Hmieleski, K.M., 2011. The downside of being “up": entrepreneurs' dispositional positive affect and firm performance. Strategic Entrepreneurship Journal, 5, $101-119$.

Bauer, I., Baumeister, R.F., 2011. Self-regulatory strength, in: Vohs, K., Baumeister, R.F. (Eds.), Handbook of Self-Regulation, second ed. Guilford Press, New York, pp. 64-82.

Baumeister, R.F., Gailliot, M., DeWall, C.N., Oaten, M., 2006. Self-regulation and personality: how interventions increase self-regulatory success, and how depletion moderates the effects of traits on behavior. Journal of Personality, 74, 1773-1802.

Baumeister, R.F., Vohs, K.D., DeWall, C.N., Zhang, L., 2007. How emotion shapes behavior: Feedback, anticipation, and reflection, rather than direct causation. Personality and Social Psychology Review, 11, 167-203.

Baumeister, R.F., Vohs, K.D., Tice, D.M., 2007. The strength model of self-control. Current Directions in Psychological Science, 16, 351-355.

Bird, B., 1988. Implementing entrepreneurial ideas: The case for intention. Academy of Management Review, 13, 442-453.

Brandstätter, V., Heimbeck, D., Malzacher, J.T., Frese, M., 2003. Goals need implementation intentions: The model of action phases tested in the applied setting of continuing education. European Journal of Work and Organizational Psychology, 12, 37-59. 
Brockner, J., Higgins, E.T., Low, M.B., 2004. Regulatory focus theory and the entrepreneurial process. Journal of Business Venturing, 19, 203-220.

Carter, N.M., Gartner, W.B., Reynolds, P.D., 1996. Exploring start-up event sequences. Journal of Business Venturing, 11, 151-166.

Carver, C.S., 2006. Approach, avoidance, and the self-regulation of affect and action. Motivation and Emotion, 30, 105-110.

Carver, C.S., Scheier, M.F., 1981. Attention and Self-Regulation: A Control Theory Approach to Human Behavior, Springer, New York.

Caska, B.A., 1998. The search for employment: Motivation to engage in a coping behavior. Journal of Applied Social Psychology, 28, 206-224.

Chang, S.-J., Witteloostuijn, A., Eden, L., 2010. From the Editors: Common method variance in international business research. Journal of International Business Studies, 41, 178-184.

Chiles, T.H., Bluedorn, A.C., Gupta, V.K., 2007. Beyond creative destruction and entrepreneurial discovery: A radical Austrian approach to entrepreneurship. Organization Studies, 28, 467-493.

Cohen, J., 1992. A power primer. Psychological Bulletin, 112, 155-159.

Conner, M., Armitage, C.J., 1998. Extending the theory of planned behavior: A review and avenues for further research. Journal of Applied Social Psychology, 28, 1429-1464.

Duckworth, A.L., Seligman, M.E.P., 2005. Self-discipline outdoes IQ in predicting academic performance of adolescents. Psychological Science, 16, 939-944.

Elliott, A.J., 2006. The hierarchical model of approach-avoidance motivation. Motivation and Emotion, 30, 111-116. 
Eyal, T., Liberman, N., Trope, Y, Walther, E., 2004. The pros and cons of temporally near and distant action. Journal of Personality and Social Psychology, 86, 781-795.

Feldman, L., Barrett, L., Russell, J.A., 1998. Independence and bi-polarity in the structure of current affect. Journal of Personality and Social Psychology, 74, 967-984.

Fitzsimmons, J.R., Douglas, E.J. 2011. Interaction between feasibility and desirability in the formation of entrepreneurial intentions. Journal of Business Venturing, 26, 431-440.

Foo, M.-D., 2011. Emotions and entrepreneurial opportunity evaluation. Entrepreneurship Theory and Practice, 35, 375-393.

Foo, M.-D., Uy, M.A., Baron, R.A., 2009. How do feelings influence effort? An empirical study of entrepreneurs' affect and venture effort. Journal of Applied Psychology, 94, 1086-1094.

Foo, M.-D., Uy, M.A., Murnieks, C., 2013. Beyond affective valence: Untangling valence and activation influences on opportunity identification. Entrepreneurship Theory and Practice, DOI: $10.1111 /$ etap.12045.

Fox, N.A., Calkins, S.D., 2003. The development of self-control of emotion: Intrinsic and extrinsic influences. Motivation and Emotion, 27, 7-25.

Frese, M., 2007. The psychological actions and entrepreneurial success: An action theory approach, in: Baum, J.R., Frese, M., Baron, R.A. (Eds.), The Psychology of Entrepreneurship. Erlbaum, Mahwah, pp. 151-188.

Frese, M., 2009. Toward a psychology of entrepreneurship: An action theory perspective. Foundations and Trends in Entrepreneurship 5, 435-494.

Gable, S.L., Reis, H.T., Elliott, A.J., 2000. Behavioral activation and inhibition in everyday life. Journal of Personality and Social Psychology, 78, 1135-1149. 
Gielnik, M.M, Frese, M., Kahara-Kawuki, A., Katono, I.W., Kyejjusa, S., Munene, J., Muhammed, N., Namatovu-Dawa, R., Nansubuga, F., Orobia, L., Oyugi, J., Sejjaaka, S., Sserwanga, A., Walter, T., Bischoff, K.M., Dlugosch, T.J., 2013. Action and actionregulation in entrepreneurship: Evaluating a student training for promoting entrepreneurship. Academy of Management Learning and Education, DOI: 10.5465/amle.2012.0107.

Gielnik, M.M., Barabas, S., Frese, M., Namatovu-Dawa, R., Scholz, F.A., Metzger, J.R., Walter, T., 2014. A temporal analysis of how entrepreneurial goal intentions, positive fantasies, and action planning affect starting a new venture and when the effects wear off. Journal of Business Venturing, 29, 755-772.

Goethner, M., Obschonka, M., Silbereisen, R.K., Cantner, U., 2012. Scientists' transition to academic entrepreneurship: economic and psychological determinants. Journal of Economic Psychology, 33, 628-641.

Gollwitzer, P.M., 1990. Action phases and mind-sets, in: Higgins, E.T., Sorrentino, R.M. (Eds.), Handbook of Motivation and Cognition: Foundations of Social Behavior (Vol. 2). Guilford Press, New York, pp. 53-92.

Gollwitzer, P.M., 1999. Implementation intentions. Strong effects of simple plans. American Psychologist, 54, 493-503.

Gollwitzer, P.M., 2001. Volition, in: Kazdin, A.E. (Ed.), Encyclopedia of Psychology. Oxford University Press, Oxford, pp. 210-214.

Gollwitzer, P. M., 2012. Mindset theory of action phases, in: Lange, P. van (Ed.), Handbook of Theories of Social Psychology. Sage, Thousand Oaks, pp. 526-545. 
Gollwitzer, P. M., Heckhausen, H., Ratajczak, H., 1990. From weighing to willing: Approaching a change decision through pre- and postdecisional mentation. Organizational Behavior and Human Decision Making Processes, 45, 41-65.

Gollwitzer, P.M., Sheeran, P., 2006. Implementation intentions and goal achievement: a metaanalysis of effects and processes. Advances in Experimental Social Psychology, 38, 69119.

Gross, J.J., 2002. Emotion regulation: Affective, cognitive, and social consequences. Psychophysiology, 3, 281-291.

Gross, J. J., Richards, J. M., \& John, O. P., 2006. Emotion regulation in everyday life, in: Snyder, D.K., Simpson, J.A., Hughes, J.N. (Eds.), Emotion regulation in couples and families: Pathways to dysfunction and health. Washington DC: American Psychological Association, pp.13-35.

Harrison, D.A., McLoughlin, M.E., Coalter, T.M., 1996. Context, cognition and common method variance: Psychometric and verbal protocol evidence. Organizational Behavior and Human Decision Process, 68, 246-261.

Hayes, A.F., 2013. Introduction to Mediation, Moderation, and Conditional Process Analysis: A Regression-Based Approach. Guilford Press, New York.

Heckhausen, H., Gollwitzer, P.M., 1987. Thought contents and cognitive functioning in motivational versus volitional states of mind. Motivation and Emotion, 11, 101-120.

Higgins, E.T., 1998. Promotion and prevention: regulatory focus as a motivational principle, in: Zanna, M.P. (Ed.), Advances in Experimental Social Psychology (Vol. 30). Academic Press, New York, pp. 1-46. 
Hu, L., Bentler, P.M., 1999. Cutoff criteria for fit indexes in covariance structure analysis: Conventional criteria versus new alternatives. Structural Equation Modeling: A Multidisciplinary Journal, 6, 1-55.

Kautonen, T., Van Gelderen, M., Fink, M., 2013. Robustness of the theory of planned behavior in predicting entrepreneurial intentions and actions. Entrepreneurship Theory and Practice, http://dx.doi.org/10.1111/etap.12056.

Krueger, N.F., Reilly, M.D., Carsrud, A.L., 2000. Competing models of entrepreneurial intentions. Journal of Business Venturing, 15, 411-432.

Lévesque, M., Minniti, M., 2006. The effect of aging on entrepreneurial behavior. Journal of Business Venturing, 21, 177-194.

Liao, J., Welsch, H., 2008. Patterns of venture gestation process: Exploring the differences between tech and non-tech nascent entrepreneurs. Journal of High Technology Management Research, 19, 103-113.

Liberman, N., Trope, Y., McCrea, S.M., Sherman, S.J., 2007. The effect of level of construal on the temporal distance of activity enactment. Journal of Experimental Social Psychology, $43,143-149$.

Lichtenstein, B.B., Carter, N.M., Dooley, K.J., Gartner, W.B., 2007. Complexity dynamics of nascent entrepreneurship. Journal of Business Venturing, 22, 236-261.

Loewenstein, G.F., Weber, E.U., Hsee, C.K., Welch, N., 2001. Risk as feelings. Psychological Bulletin, 127, 267-286.

Lord, R.G., Diefendorff, J.M., Schmidt, A.M., Hall, R.J., 2010. Self-regulation at work. Annual Review in Psychology, 61, 543-568. 
Markman, G.D., Baron, R.A., Balkin, D.B., 2005. Are perseverance and self-efficacy costless? Assessing entrepreneurs' regretful thinking. Journal of Organizational Behavior, 26, 1-19. McCrea, S.M., Liberman, N., Trope, Y., Sherman, S.J., 2008. Construal level and procrastination. Psychological Science, 19, 1308-1314.

McKelvie, A., Haynie, J.M., Gustavsson, V., 2011. Unpacking the uncertainty construct: Implications for entrepreneurial action. Journal of Business Venturing, 26, 273-292.

McMullen, J.S., Shepherd, D.A., 2006. Entrepreneurial action and the role of uncertainty in the theory of the entrepreneur. Academy of Management Review, 31, 132-152.

Metcalfe, J., Mischel, W., 1999. A hot/cool system analysis of delay of gratification: Dynamics of willpower. Psychological Review, 106, 3-19.

Milleken, F.J., 1987. Three types of perceived uncertainty about the environment: State, effect and response uncertainty. Academy of Management Review, 12, 133-143.

Mischel, W., Shoda, Y., Peake, P. K., 1988. The nature of adolescent competencies predicted by preschool delay of gratification. Journal of Personality and Social Psychology, 54, 687696.

Muraven, M.R. and Baumeister, R.F., 2000, Self-regulation and depletion of limited resources: Does self-control resemble a muscle? Psychological Bulletin, 126, 247-259.

Nunnally, J., 1978. Psychometric Theory. McGraw-Hill, New York.

Oxforddictionaries (2014). Definition of action in English. http://www.oxforddictionaries.com/definition/english/action (accessed 20 August 2014).

Quadrini, V., 2002. Entrepreneurship, saving, and social mobility. Review of Economic Dynamics, 3, 1-40 
Parker, S.C., 2009. The Economics of Entrepreneurship. Cambridge University Press, Cambridge.

Podsakoff, P.M., MacKenzie, S.B., Lee, J.Y., Podsakoff, N.P., 2003. Common method biases in behavioral research: A critical review of the literature and recommended remedies. Journal of Applied Psychology, 88, 879-903.

Preacher, K.J., 2014. A primer on interaction effects in multiple linear regression. http://www.quantpsy.org/interact/interactions.htm (accessed 16 April 2014).

Rauch, A., Frese, M., 2007. Let's put the person back into entrepreneurship research: A metaanalysis on the relationship between business owners' personality traits, business creation, and success. European Journal of Work and Organizational Psychology, 16, 353-385.

Reynolds, P.D., 2000. National panel study of U.S. business startups: Background and methodology, in: Katz, J. (Ed.), Advances in Entrepreneurship, Firm Emergence and Growth (Vol. 4): Databases for the Study of Entrepreneurship. Elsevier, Amsterdam, pp. $153-227$.

Richardson, H.A., Simmering, M.J., Sturman, M.C., 2009. A tale of three perspectives:

Examining post hoc statistical techniques for detection and correction of common method variance. Organizational Research Methods, 12, 762-800.

Rogelberg, S.G., Stanton, J.M., 2007. Understanding and dealing with organizational survey nonresponse. Organizational Research Methods, 10, 195-209.

Rotefoss, B., Kolvereid, L., 2005. Aspiring, nascent and fledgling entrepreneurs: An investigation of the business start-up process. Entrepreneurship \& Regional Development, 17, 109-127. 
Schlaegel, C., Koenig, M., 2014. Determinants of entrepreneurial intent: A meta-analytic test and integration of competing models. Entrepreneurship Theory and Practice, 38, 291-332.

Scholer, A.A., Higgins, E.T., 2013. Dodging monsters and dancing with dreams: Success and failure at different levels of approach and avoidance. Emotion Review, 5, 254-258.

Schwarz, N., Clore, G.L., 1983. Mood, misattribution, and judgments of well-being: Informative and directive functions of affective states. Journal of Personality and Social Psychology, $45,513-523$.

Schwarzer, R., 2008. Modeling health behavior change: How to predict and modify the adoption and maintenance of health behaviors. Applied Psychology: An International Review, 57, $1-29$.

Shapero, A., Sokol, L., 1982. Social dimensions of entrepreneurship, in: Kent, C., Sexton, D., Vesper, K. (Eds.), The Encyclopedia of Entrepreneurship. Prentice-Hall, Englewood Cliffs, pp. 72-90.

Sheeran, P., 2002. Intention-behaviour relations: A conceptual and empirical overview. European Review of Social Psychology, 12, 1-36.

Shoda, Y., Mischel, W., Peake, P.K., 1990. Predicting adolescent cognitive and self-regulatory competencies from preschool delay of gratification: Identifying diagnostic conditions. Developmental Psychology, 26, 978-986.

Souitaris, V., Zerbinati, S., Al-Laham, A., 2007. Do entrepreneurship programs raise entrepreneurial intention of science and engineering students? The effect of learning, inspiration and resources. Journal of Business Venturing, 22, 566-591.

Spector, P.E., 2006. Method variance in organizational research: Truth or urban legend? Organizational Research Methods, 9, 221-232. 
Steel, P., 2007. The nature of procrastination: A meta-analytic and theoretical review of quintessential self-regulatory failure. Psychological Bulletin, 133, 65-94.

Stewart, W.H., Roth, P.L., 2001. Risk propensity differences between entrepreneurs and managers: a meta-analytic review. Journal of Applied Psychology, 86, 145-153.

Tangney, J.P., Baumeister, R.F., Boone, A.L., 2004. High self-control predicts good adjustment, less pathology, better grades, and interpersonal success. Journal of Personality, 72, 271324.

Trope, Y., Liberman, N., 2003. Temporal construal. Psychological Review, 110, 403-421.

Trope, Y., Liberman, N., 2010. Construal-level theory of psychological distance. Psychological Review, 117, 440-463.

Tumasjan, A., Welpe, I. Spörrle, M., 2013. Easy now, desirable later: The moderating role of temporal distance in opportunity evaluation and exploitation. Entrepreneurship Theory and Practice, 37, 859-888.

Van Eerde, W., 2000. Procrastination: Self-regulation in initiating aversive goals. Applied Psychology: An International Review, 49, 372-389.

Van Hooft, A.J., Born, M.P., Taris, T.W., van der Flier, H., Blonk, R.W.B., 2004. Predictors of job search behaviors among employed and unemployed people. Personnel Psychology, 57, 25-59.

Welpe, I.M., Spörrle, M., Grichnik, D., Michl, T., Audretsch, D.B., 2012. Emotions and opportunities: The interplay of opportunity evaluation, fear, joy, and anger as antecedent of entrepreneurial exploitation. Entrepreneurship Theory and Practice, 37, 859-888.

Williams, $\quad$ R. 2014. Multicollinearity. Retrieved from: http://www3.nd.edu/ rwilliam/stats2/111.pdf (accessed 23 July 2014). 
Wolfe, R.N., Johnson, S.D., 1995. Personality as a predictor of college performance. Educational \& Psychological Measurement, 55, 177-185.

Xavier, S.R., Kelley, D., Kew, J., Herrington, M., Vorderwülbecke, A., 2012. Global entrepreneurship monitor 2012 global report. Global Entrepreneurship Research Association (GERA).

Zellweger, T., Sieger, P., Halter, F., 2011. Should I stay or should I go? Career choice intentions of students with family business background. Journal of Business Venturing, 26, 521-536. 
Table 1

Descriptive statistics

\begin{tabular}{|c|c|c|c|c|c|c|c|c|c|c|c|c|c|c|c|}
\hline & $\alpha$ & Min & Max & Mean & SD & 1. & 2. & 3. & 4. & 5. & 6. & 7. & 8. & 9. & 10. \\
\hline 1. Taking action & .85 & 1 & 5.67 & 1.80 & .85 & 1 & & & & & & & & & \\
\hline 2. Intention strength & .92 & 1.33 & 6 & 2.99 & 1.27 & $.35^{* *}$ & 1 & & & & & & & & \\
\hline 3. Action fear & .73 & 1 & 6 & 3.47 & 1.43 & -.06 & -.11 & 1 & & & & & & & \\
\hline 4. Action aversion & .81 & 1 & 6 & 3.24 & 1.26 & -.11 & -.08 & $.51^{* *}$ & 1 & & & & & & \\
\hline 5. Action doubt & .89 & 1 & 6 & 3.19 & 1.40 & $-.28 * *$ & -.12 & $.48 * *$ & $.54 * *$ & 1 & & & & & \\
\hline 6. Trait self-control & .82 & 2.54 & 5.69 & 4.18 & .67 & .06 & .07 & $-.19 *$ & -.15 & $-.18^{*}$ & 1 & & & & \\
\hline $\begin{array}{l}\text { 7. Saving money/ collecting } \\
\text { experience }\end{array}$ & & 1 & 6 & 3.22 & 1.68 & .08 & .05 & .12 & .14 & $.16^{*}$ & .07 & 1 & & & \\
\hline 8. Unexpected changes & & 1 & 6 & 3.39 & 1.94 & .00 & $.16^{*}$ & $.24 * *$ & .15 & .06 & -.01 & -.05 & 1 & & \\
\hline 9. Age & & 21 & 64 & 41.42 & 11.30 & $.23 * *$ & $.25^{* *}$ & -.11 & -.15 & $-.16^{*}$ & .07 & -.13 & $.18^{*}$ & 1 & \\
\hline 10. Female & & 0 & 1 & .45 & & .06 & -.09 & $.36^{* *}$ & .11 & $.16^{*}$ & -.00 & .01 & .00 & -.03 & 1 \\
\hline 11. Entrepreneurial experience & & 0 & 1 & .22 & & $.27 * *$ & .12 & $-.24 * *$ & $-.17 *$ & $-.36^{* *}$ & .03 & -.08 & .01 & $.25 * *$ & -.09 \\
\hline
\end{tabular}

Notes: $n=161$. Pearson correlation coefficients. $*$ and $* *$ denote significance at the $5 \%$ and $1 \%$ levels. $\alpha=$ Cronbach's alpha. 


\section{Table 2}

Maximum-likelihood estimates for the path model

\begin{tabular}{|c|c|c|c|c|c|c|c|c|c|c|c|c|c|c|c|c|}
\hline & \multicolumn{4}{|c|}{ (1) Controls only } & \multicolumn{4}{|c|}{ (2) Direct effects } & \multicolumn{4}{|c|}{$\begin{array}{l}\text { (3) Interactions between emotions and } \\
\text { intention strength }\end{array}$} & \multicolumn{4}{|c|}{$\begin{array}{l}\text { (4) Interaction between trait self-control } \\
\text { and intention strength }\end{array}$} \\
\hline & Action & Fear & Aver & Doubt & Action & Fear & Aver & Doubt & Action & Fear & Aver & Doubt & Action & Fear & Aver & Doubt \\
\hline \multicolumn{17}{|l|}{ Direct effects } \\
\hline Intention strength (IS) & & & & & $.30 * * *$ & & & & $.30 * * *$ & & & & $.30 * * *$ & & & \\
\hline Action fear (Fear) & & & & & .10 & & & & .10 & & & & .12 & & & \\
\hline Action aversion (Aver) & & & & & .03 & & & & .05 & & & & .06 & & & \\
\hline Action doubt (Doubt) & & & & & $-.27 * * *$ & & & & $-.28 * * *$ & & & & $-.27 * * *$ & & & \\
\hline Trait self-control (SC) & & & & & -.01 & $-.18 * *$ & $-.14^{*}$ & $-.16^{* *}$ & -.01 & $-.18^{* *}$ & $-.14 *$ & $-.16^{* *}$ & .00 & $-.18^{* *}$ & $-.14 *$ & $-.16^{* *}$ \\
\hline \multicolumn{17}{|l|}{ Interaction terms } \\
\hline Fear*IS & & & & & & & & & -.04 & & & & -.02 & & & \\
\hline Aver*IS & & & & & & & & & $.17^{*}$ & & & & $.19^{*}$ & & & \\
\hline Doubt*IS & & & & & & & & & $-.19^{*}$ & & & & $-.18^{*}$ & & & \\
\hline SC*IS & & & & & & & & & & & & & $.16^{* *}$ & & & \\
\hline \multicolumn{17}{|l|}{ Control variables } \\
\hline Saving money/collecting experience & .12 & & & & $.10^{*}$ & & & & .08 & & & & .08 & & & \\
\hline Unexpected changes & -.03 & & & & -.08 & & & & -.08 & & & & -.05 & & & \\
\hline Age & $.19 * *$ & -.06 & -.12 & -.08 & .11 & -.05 & -.11 & -.07 & .11 & -.05 & -.11 & -.07 & $.12 *$ & -.05 & -.11 & -.07 \\
\hline Age squared & .04 & .06 & .02 & .06 & .06 & .05 & .02 & .06 & .06 & .05 & .02 & .06 & .07 & .05 & .02 & .06 \\
\hline Female & .09 & $.34 * * *$ & .10 & $.13^{*}$ & .11 & $.34 * * *$ & .10 & $.13 *$ & .10 & $.34 * * *$ & .10 & $.13 *$ & .09 & $.34 * * *$ & .10 & $.13 *$ \\
\hline Entrepreneurial experience & $.24 * * *$ & $-.19^{* *}$ & -.12 & $-.32 * * *$ & $.15^{*}$ & $-.19 * *$ & -.12 & $-.32 * * *$ & $.15^{*}$ & $-.19 * *$ & -.12 & $-.32 * * *$ & $.13^{*}$ & $-.19^{* *}$ & -.12 & $-.32 * * *$ \\
\hline R-squared & .13 & .18 & .05 & .15 & .28 & .21 & .07 & .18 & .30 & .21 & .07 & .18 & .33 & .21 & .07 & .18 \\
\hline Change in R-squared & & & & & .15 & .03 & .02 & .03 & .02 & .00 & .00 & .00 & .03 & .00 & .00 & .00 \\
\hline $\begin{array}{l}\text { Chi-squared test for change in model } \\
\text { fit (compared to previous model) }\end{array}$ & & & & & \multicolumn{4}{|c|}{$28.22(8 \mathrm{df}), p<.001$} & \multicolumn{4}{|c|}{$22.35(12 \mathrm{df}), p<.05$} & \multicolumn{4}{|c|}{$8.14(4 \mathrm{df}), p<.10$} \\
\hline
\end{tabular}

Notes: $n=161$. Standardized coefficients. ${ }^{*}, *$ and $* * *$ denote $5 \%, 1 \%$ and $.1 \%$ significance levels. Estimates of the intercept terms omitted. $\mathrm{df}=\mathrm{degrees}$ of freedom. 


\section{Table 3}

Higher-order interaction between intention strength, action aversion, and action doubt

\begin{tabular}{|c|c|c|c|c|}
\hline & Action & Fear & Aver & Doubt \\
\hline \multicolumn{5}{|l|}{ Direct effects } \\
\hline Intention strength (IS) & $.40 * * *$ & & & \\
\hline Action fear (Fear) & .13 & & & \\
\hline Action aversion (Aver) & .04 & & & \\
\hline Action doubt (Doubt) & $-.28 * * *$ & & & \\
\hline Trait self-control (SC) & -.02 & $-.18^{* *}$ & $-.14^{*}$ & $-.16^{*}$ \\
\hline \multicolumn{5}{|l|}{ Interaction terms } \\
\hline Fear*IS & -.01 & & & \\
\hline Aver*IS & $.18^{*}$ & & & \\
\hline Doubt*IS & $-.16^{*}$ & & & \\
\hline SC*IS & $.13 *$ & & & \\
\hline Aver*Doubt & -.04 & & & \\
\hline Aver*Doubt*IS & $-.18^{*}$ & & & \\
\hline \multicolumn{5}{|l|}{ Control variables } \\
\hline $\begin{array}{l}\text { Saving money/collecting } \\
\text { experience }\end{array}$ & .06 & & & \\
\hline Unexpected changes & -.03 & & & \\
\hline Age & $.12 *$ & -.05 & -.11 & -.07 \\
\hline Age squared & .06 & .05 & .02 & .06 \\
\hline Female & .09 & $.34 * * *$ & .10 & $.13 *$ \\
\hline Entrepreneurial experience & $.14^{*}$ & $-.19 * *$ & -.12 & $-.32 * * *$ \\
\hline R-squared & .35 & .21 & .07 & .18 \\
\hline
\end{tabular}

Notes: $n=161$. Maximum-likelihood estimates. Standardized path coefficients. *, ** and $* * *$ denote $5 \%, 1 \%$ and $.1 \%$ significance levels. Estimates of the intercept terms omitted. 


\section{Table 4}

\section{Overview of the hypothesis tests}

\begin{tabular}{lll}
\hline Hypothesis & \multicolumn{1}{c}{ Outcome } \\
\hline 1a-c & Mixed & $\begin{array}{l}\text { Only H1a is supported: the intention-action relationship is conditional on the level } \\
\text { of action doubt. The effect of intention strength is positive and significant at a low } \\
\text { level of action doubt, whereas it is not significant at a high level of action doubt. } \\
\text { Action fear does not significantly moderate the intention-action relationship, and } \\
\text { hence H1b is not supported. Action aversion moderates the effect of intention } \\
\text { strength on taking action but in the opposite direction than hypothesized. This } \\
\text { effect is also not robust across different model specifications. Therefore, H1b is not } \\
\text { supported. Furthermore, the post hoc robustness tests suggested the existence of a } \\
\text { higher-order interaction between intention strength, aversion, and doubt such that } \\
\text { the effect of intention is strongest when aversion is high and doubt low. }\end{array}$ \\
& $\begin{array}{l}\text { The intention-action relationship is conditional on the level of self-control. The } \\
\text { effect of intention strength is positive and significant at a high level of trait self- } \\
\text { control, whereas it is not significant at a low level of trait self-control. }\end{array}$ \\
& Trait self-control exerts a negative and statistically significant effect on action fear, \\
& action aversion, and action doubt. \\
\hline \multirow{3}{*}{ Supported } &
\end{tabular}


Fig. 1. Research hypotheses

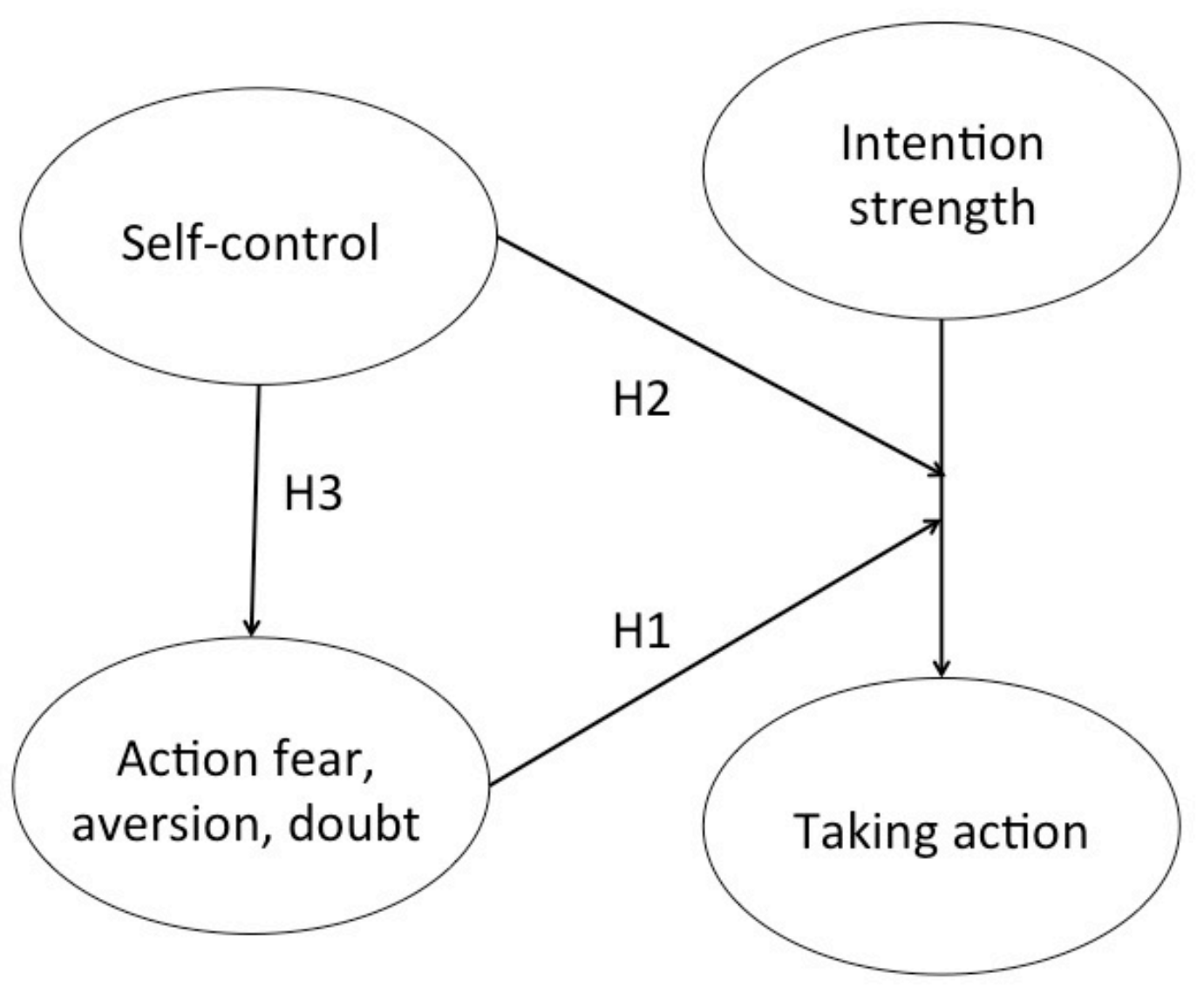


Fig. 2. Plot of the interaction between action aversion and intention strength

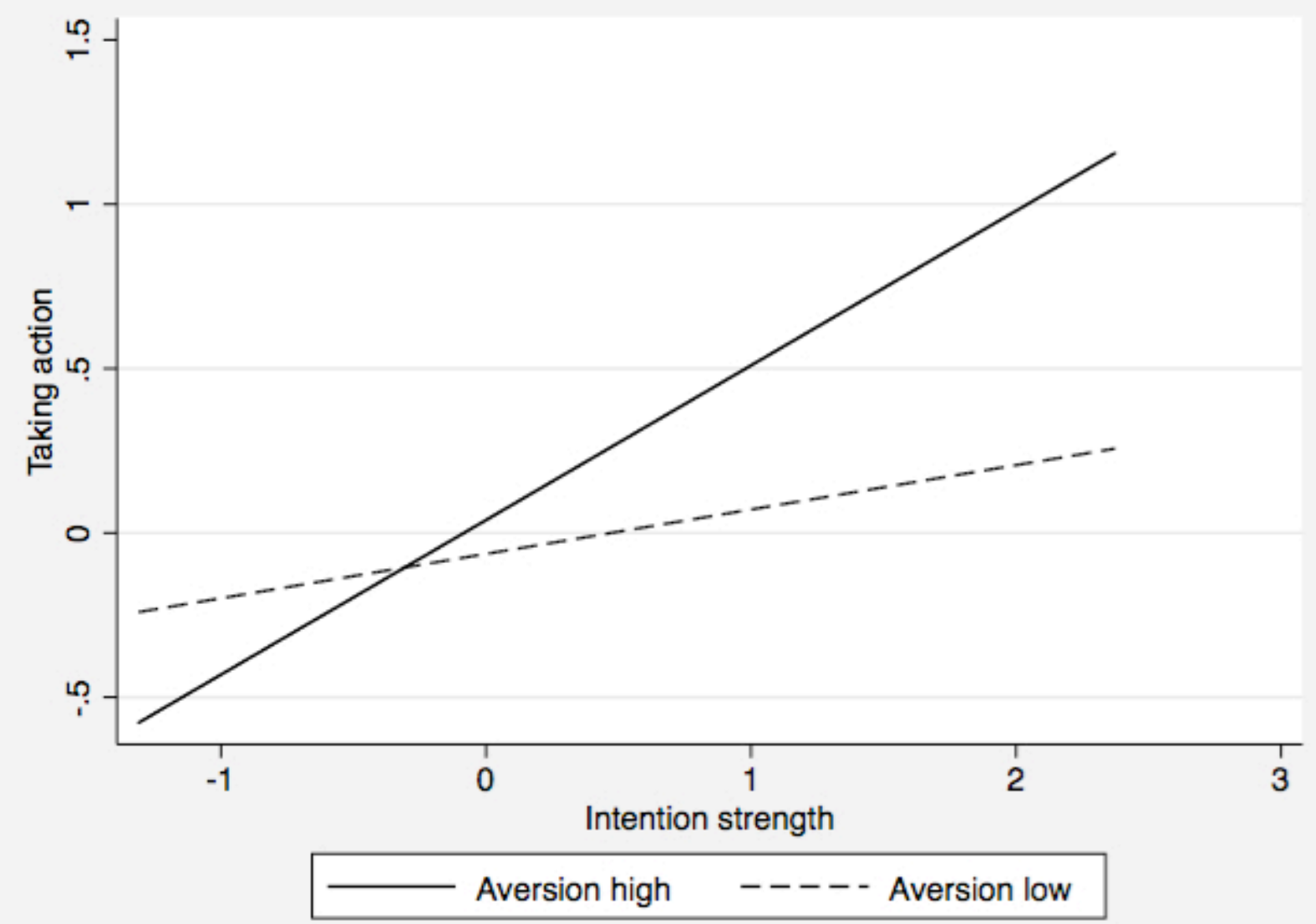

Notes: The marginal effect (simple slope) of intention strength is $.47(t=3.77, p<.001)$ when action aversion is high ( $+1 \mathrm{SD})$ and $.14(t=1.01$, n.s. $)$ when action aversion is low (-1 SD). 
Fig. 3. Plot of the interaction between action doubt and intention strength

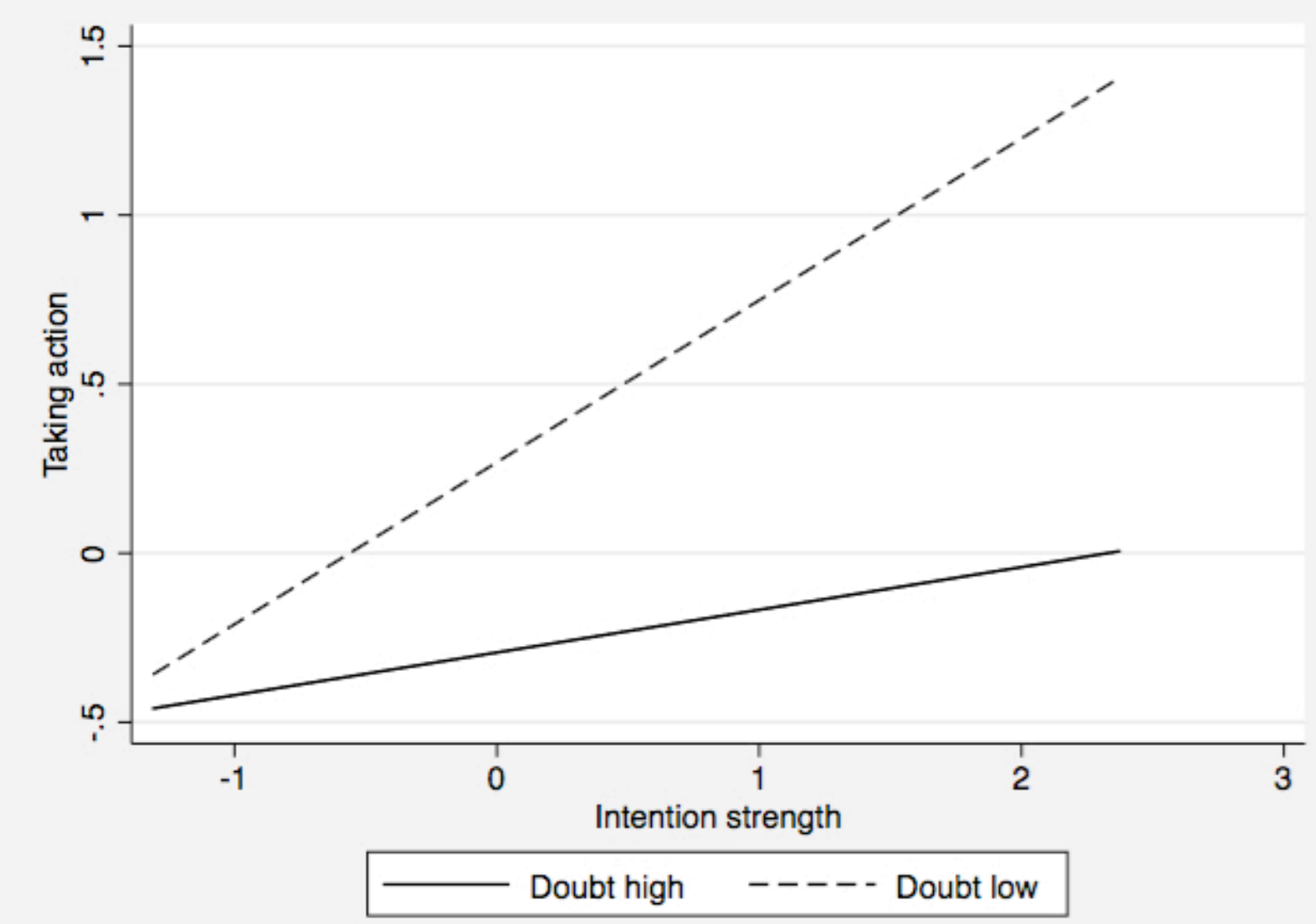

Notes: The marginal effect (simple slope) of intention strength is .13 ( $t=1.07$, n.s.) when action doubt is high $(+1 \mathrm{SD})$ and $.48(t=3.88, p<.001)$ when action doubt is low $(-1 \mathrm{SD})$. 
Fig. 4. Plot of the interaction between trait self-control and intention strength

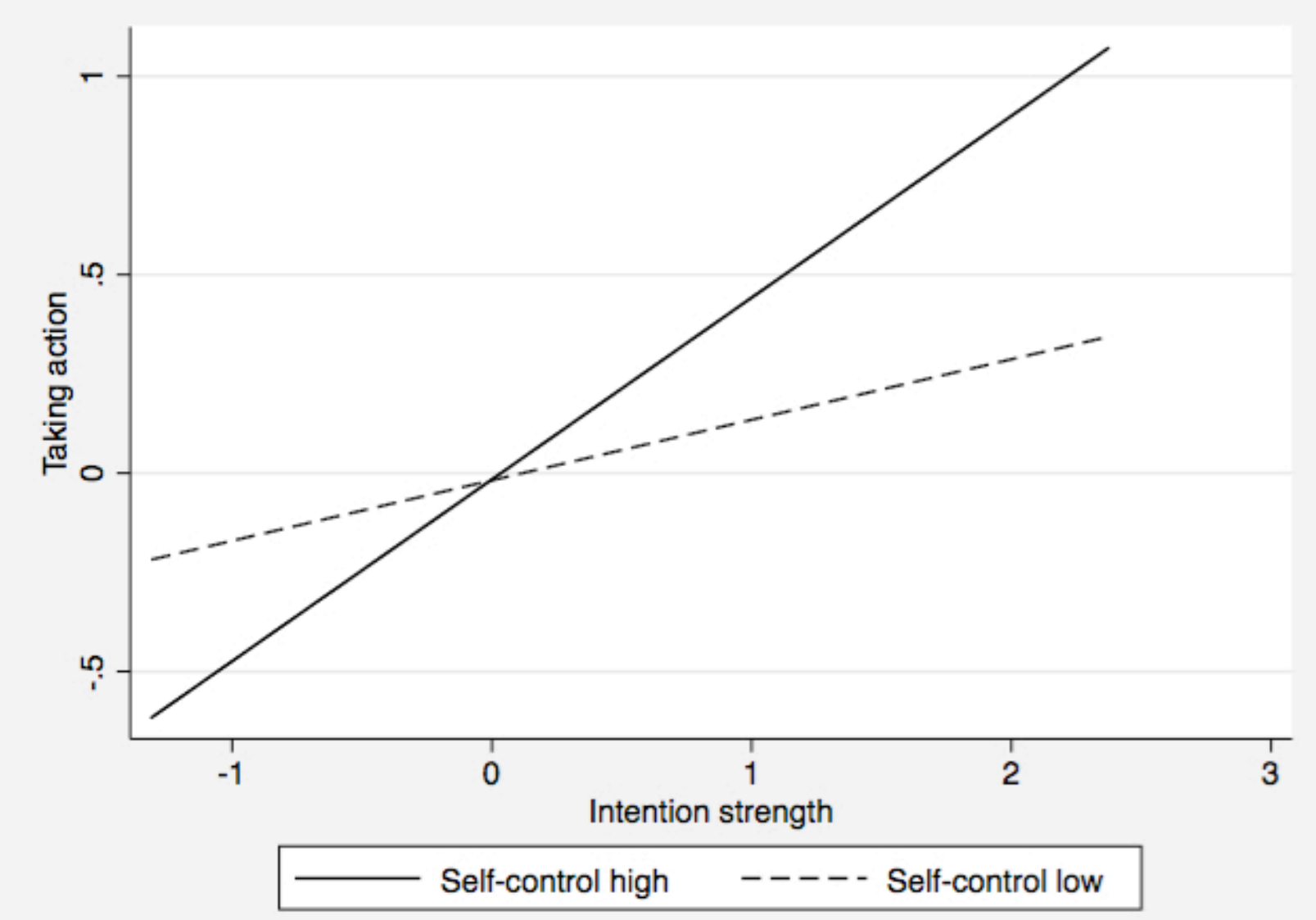

Notes: The marginal effect (simple slope) of intention strength is .46 $(t=4.46, p<.001)$ when trait self-control is high ( $+1 \mathrm{SD})$ and .15 ( $t=1.51$, n.s.) when trait self-control is low (-1 SD). 
Fig. 5. Plot of the interaction between action aversion, action doubt, and intention strength

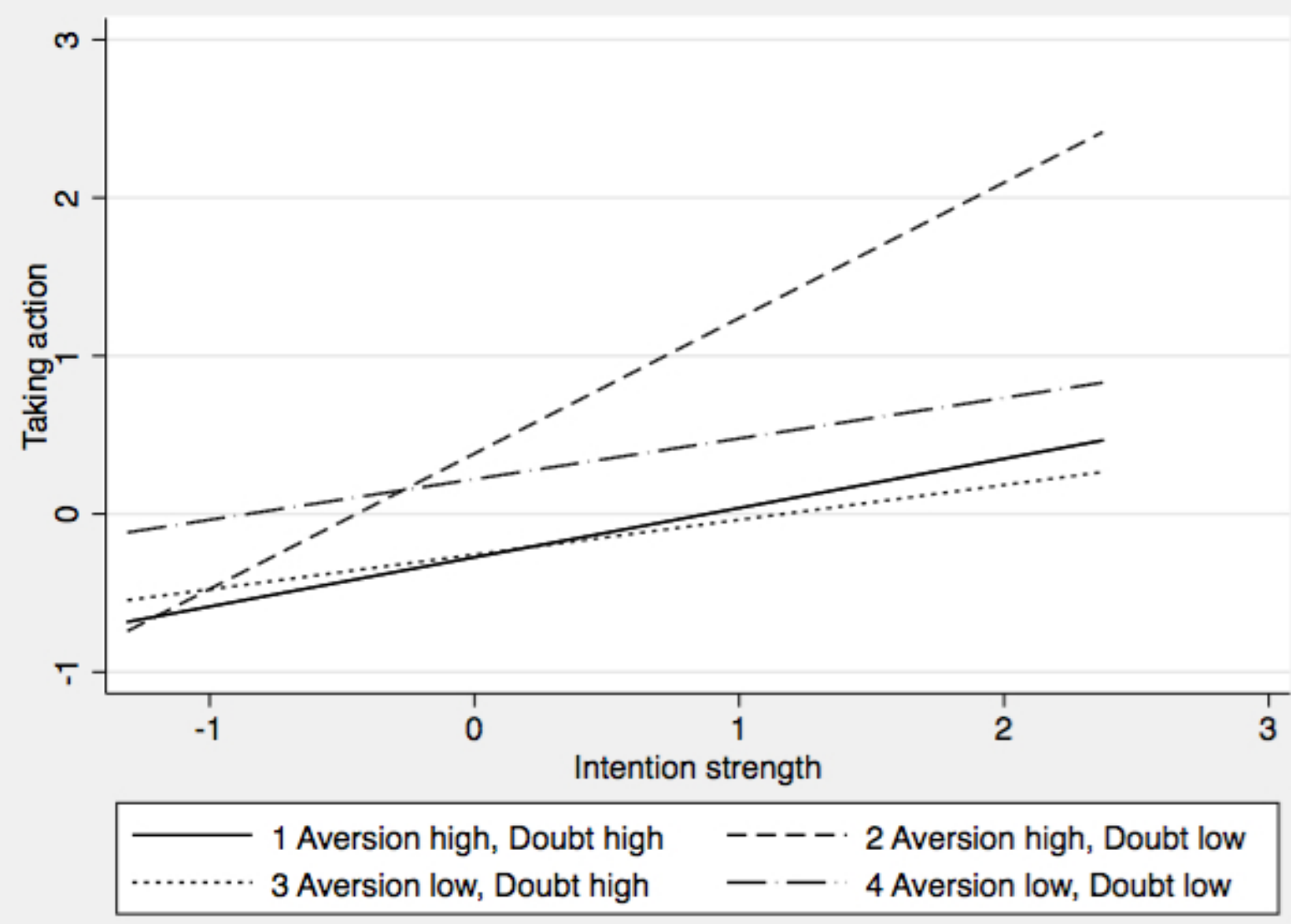

Notes: The marginal effect (simple slope) of intention strength is .31 $(t=2.70, p<.01)$ when (1) action aversion and action doubt are both high (+1 SD); (2) $.85(t=4.08, p<.001)$ when action aversion is high (+1 SD) and action doubt is low (-1 SD); (3) $.22(t=.98$, n.s.) when action aversion is low (-1 SD) and action doubt is high (+1 SD); and (4) .26 $(t=1.96, p<.05)$ when action aversion and action doubt are both low (-1 SD). The difference between the simple slope of "(2) aversion high, doubt low" and all the other simple slopes is significant at least at the $p<.05$ level. The differences between the other three simple slopes are not statistically significant. 